\title{
Autocrine Signaling by Receptor Tyrosine Kinases in Urothelial Carcinoma of the Bladder
}

Young H. Lee, Molly M. Lee, Dinuka M. De Silva, Arpita Roy, Cara Wright, Tiffany Wong, Rene Costello, Oluwole Olaku, Robert L. Grubb III\#, Piyush K. Agarwal, Andrea B. Apolo*+ Donald P. Bottaro*

Urologic Oncology Branch and +Genitourinary Malignancies Branch, Center for Cancer Research, National Cancer Institute, National Institutes of Health, Bethesda, Maryland 20892 USA and

\#Department of Urology, Medical University of South Carolina, Charleston, South Carolina 29425 USA;

*Equal contributions and to whom correspondence should be addressed: don.bottaro@nih.gov (ORCID ID: 0000-0002-5057-5334) or andrea.apolo@nih.gov 
Running Title: Autocrine Signaling by Receptor Tyrosine Kinases in Bladder Cancer

Funding Sources: This work was supported by the Intramural Research Program of the Center for Cancer Research, National Cancer Institute, National Institutes of Health (URL https://ccr.cancer.gov/), through grant awards ZIA-BC011095-12 and ZIA-BC011124-12 to DPB. The funders had no role in study design, data collection and analysis, decision to publish, or preparation of the manuscript.

Conflict of Interest Statement: D Bottaro is an inventor on US Government held patents: US 10,035,833, 9,550,818 and related international WO/2013/163606; US 8,617,831, 8,569,360 and related international WO/2009/124024, 124013; US 8,304,199, 7,964,365 and related international WO/2007/056523; and US 7,871,981 and related international WO/2001/028577 for inventions related to MET detection and inhibition, VEGFR inhibition, methods to detect and diagnose cancer, and methods to inhibit cell motility and tumor metastasis. No other authors have competing interests to disclose.

Keywords: Urothelial carcinoma of the bladder, bladder cancer, receptor tyrosine kinase; tyrosine kinase inhibitor; cabozantinib.

Abbreviations: TK, tyrosine kinase; RTK, receptor TK; ctRTK, cabozantinib-targeted RTK; TKI, TK inhibitor; BCa, bladder cancer; MIBC, muscle-invasive baldder cancer; OS, overall survival; PFS, progression-free survival; TCGA, The Cancer Genome Atlas; EMT epithelial-to-mesenchymal transition; TA, transcriptional activator.

Figures: 6; Supplement Figures: 2, Supplement Tables:9 


\section{Abstract}

Comprehensive characterizations of bladder cancer (BCa) have established molecular phenotype classes with distinct alterations and survival trends. Extending these studies within the tyrosine kinase (TK) family to identify disease drivers could improve our use of TK inhibitors to treat specific patient groups or individuals. We examined the expression distribution of TKs as a class $(n=89)$ in The Cancer Genome Atlas (TCGA) muscle invasive BCa data set $(n>400)$. Patient profiles of potentially oncogenic alterations (overexpression and/or amplification) clustered TKs into 3 groups; alterations of group 1 and 3 TKs were associated with significantly worse patient survival relative to those without alterations. Many TK pathways induce epithelial-tomesenchymal transition (EMT), which promotes tumor invasiveness and metastasis. Overexpression and/or amplification among 9 EMT transcriptional activators occurred in $43 \%$ of TCGA cases. Co-occurring alterations of TKs and EMT transcriptional activators involved most group 1 TKs; 24\% of these events were associated with significantly worse patient survival. Cooccurring alterations of receptor TKs and their cognate ligands occurred in 16\% of TCGA cases and several BCa-derived cell lines. Suppression of GAS6, MST1 or CSF1, or their respective receptors (AXL, MST1R and CSF1R), in BCa cell lines was associated with decreased receptor activation, cell migration, cell proliferation and anchorage independent cell growth. These studies reveal the patterns and prevalence of potentially oncogenic TK pathway-related alterations in BCa and identify specific alterations associated with reduced BCa patient survival. Detection of these features in BCa patients could better inform TK inhibitor use and improve clinical outcomes. 


\section{Introduction}

In 2018, 549,000 new cases of bladder cancer (BCa; urothelial (transitional) cell carcinoma of the bladder) and 200,000 bladder cancer-related deaths were estimated worldwide [1]. Although $70 \%$ of newly diagnosed disease is confined to the mucosa, recurrence and progression are frequent, and long-term surveillance is required. The remaining $30 \%$ of new cases are more advanced, involving muscle invasion, lymph node involvement or distant metastases (mUC). Standard of care combination platinum-based chemotherapy for mUC patients provides a median overall survival (OS) of 9-15 months $[3,4]$. Five immune checkpoint inhibitors have been approved by the U.S. Food and Drug Administration (FDA) in the past 3 years for platinumrefractory patients [5-8], 2 of which are also approved as first-line therapy for cisplatin-ineligible mUC patients with high levels of programmed death-ligand 1 protein $[9,10]$. Despite some durable responses, the overall response rate to these therapies is 14-23\% [5-9]. More recent FDA approvals of erdafitinib for platinum refractory mUC patients with gene alterations of FGFR3 or FGFR2, and enfortumab vedotin for platinum- and immune checkpoint inhibitor-refractory mUC patients $[11,12]$ represent continued progress, but more effective identification and targeting of pathways that drive oncogenesis in this disease is urgently needed.

Several comprehensive molecular interrogations of BCa patient tumor samples have improved our understanding of disease pathogenesis, revealed functionally relevant molecular phenotypes with parallels to those of other cancers, and provided a foundation for more detailed analyses of specific signaling pathways as likely oncogenic drivers among these phenotypes and in individuals [13-21]. With the goal of identifying targets for molecular diagnosis and treatment where diagnostic reagents and targeted drugs already exist, we found that positive interim results from a phase II NCI clinical trial of the multikinase inhibitor cabozantinib for patients with advanced BCa (NCT01688999) implicated several members of the tyrosine kinase (TK) superfamily in disease progression [22]. We surveyed 12 BCa-derived cell lines for evidence of oncogenic signaling by a perceived primary cabozantinib target, MET, the receptor TK (RTK) for hepatocyte growth factor (HGF) [23]. No MET gene alterations or copy number variations among these cells lines are recorded in COSMIC [24], none of the cell lines produced HGF [23], and significant co-overexpression of MET and HGF transcripts occurred only twice in the recent TCGA data (408 cases) analyzed by Robertson et al. [21], suggesting that ligand independent or 
autocrine MET signaling occurs infrequently in BCa. In fact, evidence indicated that cabozantinib targets other than MET were active in BCa cell lines, a finding that was reinforced by the lack of any significant association between tumor tissue MET content or kinase activation and outcome in trial NCT01688999 [22].

The reported cabozantinib targets include 15 RTKs encoded by AXL, CSF1R, FLT1, FLT3, FLT4, KDR, KIT, MET, MERTK, MST1R, NTRK1, NTRK2, RET, ROS1 and TEK [25-33]. We report here results of kinase profiling of cabozantinib in vitro that implicate the 4 RTKs encoded by DDR1, DDR2, NTRK3 and TYRO3 as additional high affinity targets. We found that potentially oncogenic gene alterations (amplification, overexpression and/or mutation) of these 19 cabozantinibtargeted RTKs (ctRTKs) occur in 66\% of 408 cases in the TCGA BCa database analyzed by Robertson et al. [21], as determined using tools available on the cBioPortal [34]. RNASeq and gene amplification data in this set for $A X L, C S F 1 R, D D R 2, K D R, M S T 1 R, P D G F R A$ and TEK show significant co-occurrence of $>2$-fold expression and/or gene amplification for 8 cognate ligands of these receptors in a combined $16 \%$ of cases, suggestive of oncogenic autocrine RTK activation. Results obtained using BCa-derived cell lines indicate that autocrine signaling via the GAS6/AXL, MST1/MST1R, or CSF1/CSF1R pathways drives cell migration and proliferation, effects that were suppressed by ligand- or RTK-specific RNAi and blocked by cabozantinib. These findings reveal the prevalence and patterns of autocrine RTK signaling in BCa and suggest that detection of these events in BCa patients could better inform TK inhibitor (TKI) use and thereby improve clinical outcomes. 


\section{Materials and Methods}

Reagents

Tissue culture media and supplements were obtained from Invitrogen (Carlsbad, California USA). Antibodies against phospho-Met (1234/1235), pErk, tErk, pAkt, tAkt, AXL, MST1R, DDR1, DDR2, PTK7, RYK, MERTK and GAPDH were obtained from Cell Signaling Technology (Danvers, Massachusetts USA). Antibodies against CSF1, CSF1R and GAS6 were obtained from R\&D Systems (Minneapolis, Minnesota USA). Cabozantinib and TP0903 were obtained from the Repository of Chemical Agents - Small Molecules and Isolated Natural Products of the Developmental Therapeutics Program, Division of Cancer Treatment and Diagnosis, National Cancer Institute, Bethesda, Maryland USA (https://dtp.cancer.gov/repositories/).

\section{TCGA Database Analyses}

mRNA expression data of tumor samples from muscle-invasive bladder cancer (MIBC) patients described in the dataset analyzed by Robertson et al. [21], was downloaded using the GDC Data Portal (https://portal.gdc.cancer.gov/; April through September 2019) as RNA SeqV2 Level 3 files. The same dataset was also analyzed using tools available on the cBioPortal website [34] for gene mutations, copy number alteration (GISTIC 2.0) and mRNA expression level (absolute z-score 2 2-fold; RNA Seq V2 RSEM) for selected TKs, cognate ligands and transcription factors. Cooccurrence of gene amplification and/or overexpression was evaluated by Fisher's exact test with significance at $\mathrm{p}<0.05$ and $\mathrm{q}<0.05$. Overall and progression-free survival for cases with and without alterations was assessed by the Kaplan-Meier method and compared by log-rank test. RNA Seq data was imported into Qlucore Omics Explorer software (versions 3.0 - 3.5, Qlucore AB, Lund, Sweden) to identify differential gene expression patterns with selected $\mathrm{p}$ and q values, perform 2-group and multi-group statistical tests, and produce heat maps with clustering by specific annotations (e.g. molecular phenotype classifications defined previously [21]) as noted in the text.

\section{Gene Silencing and RT-PCR}

All siRNA used for in vitro studies were synthesized by GE Dharmacon (Lafayette, Colorado USA). siRNA transfections used Lipofectamine RNAiMax according to the manufacturer's protocol 
(Thermo Fisher Scientific, Waltham, Massachusetts USA). For quantitative RT-PCR measurements, total RNA was obtained using the RNeasy kit (Qiagen, Valencia, California USA) and concentrations were determined spectroscopically at $260 \mathrm{~nm}$ using a NanoDrop ND-1000 (Thermo Fisher Scientific). Real-time quantitative PCR was performed using a QuantStudio 6 Flex real-time PCR system (Applied Biosystems, Foster City, California USA) following manufacturer's protocols. Relative gene expression levels were evaluated using the delta-delta CT method. Absolute mRNA copy number was determined for selected targets in BCa cell lines by using purified mRNA for RTqPCR reactions and including parallel samples for PCR amplification of the neomycin gene in serial dilutions of pcDNA 3.1 plasmid. Neomycin gene PCR results were used to generate a reference standard curve relating PCR product concentration to cycle number and comparing the last cycle number at exponential product generation $(\mathrm{Cq})$ for all other reactions to that of the reference standard. Selected PCR reactions were analyzed on 1.5\% agarose gels in Tris-EDTA buffer and bands were visualized using ethidium bromide.

\section{SDS-PAGE, Immunoblot Analysis and 2-site Immunoassays}

Cells were washed with cold PBS, extracted in Laemmli buffer, sonicated, and heated for 5 min at $95{ }^{\circ} \mathrm{C}$ prior to SDS-PAGE and electrophoretic transfer to nitrocellulose or PVDF membrane. Membranes were processed as described previously [23] prior to ECL detection (Pierce/Thermo Fisher Scientific). Imaging and quantitation of ECL light emission was performed using an Azure Biosystems c600 imaging system (Dublin, California USA). Electrochemiluminescent 2-site immunoassays for Met and Axl total protein and phosphoprotein content in Triton X-100 cell extracts were performed in 96-well format as described previously [35]. Electrochemiluminescent immunoassays for Akt, Erk and phosphorylated forms of these proteins were performed in 96well format using kits available from Meso Scale Discovery (Gaithersburg, Maryland USA); all immunoassays were read using a Meso Sector S 600 instrument (Meso Scale Discovery).

\section{Assays of Cell Migration, Cell Proliferation and Anchorage-Independent Growth}

Migration assays were performed using 8- $\mu \mathrm{m}$ pore size Corning Transwell inserts (Corning, New York USA) according to the manufacturer's instructions. Images were captured by light microscopy and image analysis and quantitation were performed using Image J software V1.47 
(National Institutes of Health, Bethesda, Maryland USA). For proliferation assays, cells were transfected with siRNA negative control, siAXL, siGas6, siMST1R or siMST1 and plated in triplicate at a density of $2.5 \times 10^{4}$ cells/35 mm dish in defined medium. Gas6, MST1, and/or cabozantinib were added on days 1, 2, and 4. Cells were detached and counted using a hemocytometer on day 3 or 6. Anchorage independent growth was measured as described previously [35] with the following modifications: A base layer of 0.5\% Noble agarose (Difco, Franklin Lakes, New Jersey USA) in phenol red-free DMEM was added to 96 well plates. Cells in 0.3\% agarose in phenol redfree DMEM were added on top of the base layer. Cells were fed with DMEM with or without growth factors (as noted in the text) and cabozantinib every other day. After 1 week, MTT was added to quantify the viable colonies by absorbance using a PerkinElmer Victor plate reader (PerkinElmer, Hopkinton, Massachusetts USA). Significant differences between 2 groups were determined by Student's t test using GraphPad Prism software versions 6 - 8, where p $<0.05$ was considered statistically significant.

\section{Tumorigenicity Studies in Mice}

All experiments involving animals were performed in accordance with NIH Guidelines for Care and Use of Laboratory Animals and conforming to ARRIVE guidelines using institutionally reviewed and approved protocol UOB-009 at the Center for Cancer Research, National Cancer Institute, Bethesda, Maryland USA. J82 and derived cell lines were injected subcutaneously into SCID/BEIGE mice (Charles River Laboratories, Wilmington, Massachusetts USA; $\mathrm{n}=10$ per group) and tumor volumes were measured at regular intervals as described previously [23]. Animals were sacrificed and tumors removed for cell culture by conventional methods. Tumor growth curves were fitted by regression analysis using GraphPad Prism software versions 6 - 8.

\section{Nanostring mRNA Expression, Qlucore Omics Explorer and Ingenuity Pathway Analyses}

The Nanostring PanCancer Progression 770 gene expression panel (Nanostring Technologies Inc, Seattle, Washington USA) was used to analyze J82 cells and the J82 tumor xenograft-derived cell line MDXC1. Cells were grown to near confluence, serum-deprived for $16 \mathrm{~h}$, total RNA was extracted and samples were processed and analyzed per the manufacturer's protocol. Hybridized panels (770 genes and 30 control genes) were read at maximum field count (555 FOV). Data was normalized using Nanostring NSolver software versions 2.0 or 3.0 with a 
background threshold set to 20 counts, normalization reference set to housekeeping (control) genes, and normalization factor set to geometric mean. NSolver normalized expression data from J82 and MDXC1 cell lines was imported into Qlucore Omics Explorer software V3.0 - 3.6 for 2group comparisons with J82 samples set to control and filtering for $\mathrm{q} \leq 0.05$ and $\mathrm{p} \leq 0.0021$, generating a list of 321 significantly differentially expressed genes and heatmap with hierarchical clustering. Expression array data have been deposited in the Gene Expression Omnibus (GEO) database of the National Center for Biotechnology Information, National Library of Medicine, National Institutes of Health (URL: https://www.ncbi.nlm.nih.gov/geo/), Series GSE156348.

For Ingenuity Pathway Analysis (https://www.qiagenbioinformatics.com /products/ingenuitypathway-analysis, Qiagen NV, Venlo, Netherlands), the Nanostring 770 gene data file was uploaded and pre-processing statistical cutoffs were set to $q \leq 0.05$ and $p \leq 0.0021$, enabling IPA to identify the same 321 gene list produced by Qlucore as "analysis ready". The list was then processed using IPA Core Analysis (version 49932394, Nov 2019) with the following settings: Reference set = user data file (770 genes); Relationship to include: Direct and Indirect; Does not Include Endogenous Chemicals; Data Sources $=$ All; Species $=$ All; Tissues and Cell Lines $=$ All; Mutation = All; Filter Summary: Consider only relationships where confidence = Experimentally Observed; no cutoffs were set for fold change or ratio. P values for overlap between gene expression changes and IPA Molecule Groups, Functions, Activities or Pathways were derived using the right-tailed Fisher's exact test with Benjamini and Hochberg multiple test correction where appropriate. A positive IPA z-score indicates direct concordance between the direction (expression increase or decrease) and of genes altered in the sample and genes included in the IPA subcategory, a negative score indicates an inverse concordance. The IPA z-score is unrelated to the magnitude of expression change, provided it exceeds a threshold defined on the basis of p-value and q-value (false discovery rate). 


\section{Results}

TK Gene Expression in BCa TCGA Samples and BCa Cell Lines

Data from muscle-invasive bladder cancer (MIBC) tumor samples in the bladder urothelial carcinoma TCGA dataset analyzed by Robertson et al. [21] were analyzed using cBioPortal tools [34] and downloaded for further analyses. Samples with RNA Seq V2 data $(n=408)$ were queried for potentially oncogenic alterations (excluding mutations) in 89 TKs (>98\% of the human protein tyrosine kinome, Supplement Table S1), which occurred at combined frequencies of 53\% for gene amplification, 97\% for mRNA overexpression with z-score $>2$, and 55\% for overexpression with zscore $>4$ (Supplement Table S2A). Collectively these alterations were not associated with significant survival differences at $\log$-rank $\mathrm{p}<0.05$, but trends of lower OS and disease-free survival (DFS) for the altered groups were noted (Supplement Table S2A).

The mRNA expression profiles of 52 TKs varied significantly among the 5 molecular phenotypes of BCa developed previously [21]: neuronal (N), basal squamous (BS), luminal (L), luminal infiltrating (LI), and luminal papillary (LP), forming 2 distinct patterns (Fig. 1A). Thirtyone TKs $(A B L 1 / 2, A X L, B T K, C S F 1 R, D D R 2, E P H A 3$, EPHB2/3/4, FER, FGFR1, FLT3, FYN, HCK, IGF1R, ITK, JAK1/2/3, LCK, LYN, MET, PDGFRA/B, PTK7, ROR1/2, TEK, TIE1 and ZAP70, hereafter referred to as group 1) were highly expressed in the worse OS phenotypes $\mathrm{N}$ and BS, with lower expression in LP, the best OS phenotype, whereas 21 TKs (DDR1, EPHA1, EPHB6, ERBB2/3/4, FGFR2/3, INSR, LMTK2, MERTK, MST1R, PTK2/6, SRC, SRMS, STYK1, TNK1/2, TXK, and TYK2, hereafter group 2) showed a reciprocal expression pattern among those phenotypes $\left(\mathrm{p}=1.00 \times 10^{-4}, \mathrm{q}=1.01 \times 10^{-4}\right.$, $F_{2,405} \geq 9.42, R^{2} \geq 0.044$ for the 3 -group comparison $F$ test: LP vs. (LI+L) vs. (BS+N); Fig. 1). The expression profiles of the remaining 37 TKs varied independently of molecular phenotype (hereafter group 3; Supplement Table S1).

The frequency of potentially oncogenic alterations (excluding mutations) in these $3 \mathrm{TK}$ groups was similar: significant mRNA overexpression (z-score $>2$ ) and/or gene amplification of group 1 TKs occurred in 67\% of samples, among group 2 TKs in 69\% of samples and among group 3 TKs in 74\% of samples (Supplement Table S3A - C). However, significant $(q<0.05)$ co-occurrence of these alterations was disproportionately higher among group 1 TKs: there were 422 mRNA overexpression and/or gene amplification co-occurrences in 63 of 465 (14\%) of group 1 TK pairings (Supplement Table S3A), vs. 114 co-occurrences in 12 of 210 (6\%) of group 2 TK pairings 
(Supplement Table S3B), and 115 co-occurrences in 16 of 666 (2.4\%) of group 3 TK pairings (Supplement Table S3C). Median OS and DFS for patients harboring these alterations relative to those without alteration also differed among the TK groups, and were consistent with reported OS differences [21] between molecular phenotypes. Patients with overexpression (z-score >2) and/or gene amplification of group 1 TKs (most frequent in N and BS phenotypes) had significantly worse median OS (28.22 vs. 61.40 mos., log-rank p=0.0308) and DFS (27.99 vs. 82.42 mos., log-rank p=0.0145; Supplement Table S2B, Fig. 2A) than those without alteration, whereas patients with these alterations in group 2 TKs (most frequent in L, LI and LP phenotypes) had significantly better median OS (46.65 vs. 22.14 mos., log-rank p=3.197e-4) and DFS (51.41 vs. 19.05 mos., logrank $\mathrm{p}=6.673 \mathrm{e}-4$ ) than those without alteration (Supplement Table S2C, Fig. 2B). Patients with overexpression (z-score >2) and/or amplification of group 3 TKs, which varied independent of molecular phenotype, showed a trend of worse median OS (30.91 vs. 59.26 mos., log-rank p=0.134) and significantly worse median DFS (27.99 vs. 72.34 mos., log-rank p=0.0391) than those without alteration (Supplement Table S2D, Fig. 2C).

The TK expression profiles of 15 BCa-derived cell lines were compared to those of TCGA tumor samples using mRNA copy number for 31 TKs from groups 1 and 2 (Fig. 3A). TCGA sample profiles for this TK subset retained the same significant correlation with molecular phenotype as the parent 52 TK set $\left(\mathrm{p}=1.00 \times 10^{-4}, \mathrm{q}=8.97 \times 10^{-5}, \mathrm{~F}_{2,405} \geq 9.42, \mathrm{R}^{2} \geq 0.044\right.$ for the 3-group comparison F test: LP vs. $(\mathrm{LI}+\mathrm{L})$ vs. $(\mathrm{BS}+\mathrm{N})$; Fig. $3 \mathrm{~A})$. Each cell line profile was correlated with each TCGA sample profile, correlation coefficients were averaged within each molecular phenotype, and cell lines were assigned to N, BS, LI, L or LP phenotype by best average coefficient that was distinguished from coefficients for other phenotypes by t-test (Table 1). By these criteria, 10 of the 15 cell lines were assigned to a single phenotype or 2 related phenotypes, whereas the remaining 5 failed the t-test threshold but most closely resembled a single phenotype (Table 1). The same classification was generated using the related method of hierarchically clustering cell TK mRNA profiles by heat map (Fig. 3A, right).

Positive interim results from our phase II clinical trial of the multikinase inhibitor cabozantinib for patients with advanced BCa (NCT01688999) [22], prompted us to analyze TKs targeted by cabozantinib in the TCGA MIBC dataset [21]. The 16 reported cabozantinib targets (encoded by AXL, CSF1R, FLT1, FLT3, FLT4, KDR, KIT, MET, MERTK, MST1R, NTRK1, NTRK2, RET, ROS1, TEK and TYRO3) had been identified in a variety of ways [25-33]. We compared targets on a 
single assay platform using cell-free cabozantinib dose-dependence studies to obtain $\mathrm{IC}_{50}$ values for 30 RTKs encompassing known targets (except TEK) and members of structurally related RTK subfamilies (Fig. 3B). In this context, cabozantinib inhibited 17 RTKs with $\mathrm{IC}_{50}$ values below 150 nM, 3 of which (DDR1, DDR2, and NTRK3) were not previously reported (Fig. 3B). IC50 values could not be determined for RYK, ROR1/2 and PTK7; these RTKs as well as others with IC 50 values >300 nM were not interrogated further.

All 19 ctRTKs displayed potentially oncogenic alterations (overexpression, amplification and mutations unclassified as to pathogenic consequence) harbored by 282/408 (69\%) of cases in the MIBC TCGA dataset [21] and ranging in frequency from 4\% (NTRK2/3, TYRO3) to 20\% (DDR2); homozygous deletions were rare by comparison, affecting 13 of these genes in 51/408 (12.5\%) of cases (Fig. 3C). The mRNA expression distributions for 9 of 19 ctRTKs were significantly different among BCa molecular phenotypes; of these, 6 were group 1 TKs (AXL, CSF1R, DDR2, FLT3, MET and TEK) and 3 were group 2 TKs (DDR1, MERTK and MST1R; Fig. 1A); the remaining 10 ctRTKs (FLT1/4, KDR, KIT, NTRK1/2/3, RET, ROS1 and TYRO3) were in TK group 3. Significantly cooccurring potentially oncogenic alterations (overexpression, amplification and mutations unclassified as to pathogenic consequence, 150 events) involved 15/171 (9\%) of ctRTK pairings; these events involved only TK groups 1 (67\% of events) and 3 (33\% of events; Supplement Table S3D, top). All 15 BCa-derived cell lines examined above expressed 1 or more ctRTK (Fig. 3A, right). Patients harboring overexpression and/or amplification among 14 ctRTKs (46\% of cases) had significantly worse OS (25.56 vs. 54.86 mos., log-rank p=0.0289) and DFS (25.23 vs. 55.16 mos., $\log$-rank p=0.0109) than those without alteration (Supplement Table S2E, Fig. 2D). Significantly co-occurring alterations in the 14 ctRTKs (60 events in $6.6 \%$ of pairings) involved $A X L, C S F 1 R$, DDR2, MET, TEK, KDR and NTRK1 (Supplement Table S3D, bottom). Several ctRTKs showed general concordance between mRNA content (Fig. 3A, right) and protein abundance detected by immunoblotting (not shown) or 2-site immunoassay (Fig. 3D).

\section{Potential Autocrine RTK Signaling Pathways in BCa Tumors and Cell Lines}

cBioPortal tools were used to identify significant co-occurrence of mRNA overexpression (>2-fold RNASeqV2 z-scores) and/or gene amplification for specific RTK/cognate ligand pairs in 65/408 cases (16\%) in the TCGA dataset [21] involving 7 RTKs (AXL, CSF1R, DDR2, KDR, MST1R, PDGFRA and TEK), suggestive of oncogenic autocrine RTK signaling (Table 2A). For these RTKs 
and NTRK2, heat map analysis also revealed broad concordance between receptor and cognate ligand expression levels among BCa TCGA cases, including 5 ligands of DDR2 (COL1A1, COL3A1, COL4A1, COL5A1 and COL10A1) (Fig. 4A, left). Quantitative mRNA analyses for these ligand transcripts revealed a similar pattern of co-expression of $A X L / G A S 6, C S F 1 R / C S F 1, D D R 2 / C O L-1 A 1$, $-3 A 1,-4 A 1,5 A 1,-10 A 1, M S T 1 R / M S T 1$, and NTRK2/NTF4 in a combined 20\% of 15 BCa-derived cell lines (Fig. 4A, right). Receptor/ligand co-expression events were confirmed by immunoblot analysis for CSF1R/CSF1, AXL/GAS6, and MST1R/MST1 in 9 BCa cell lines (Fig. 4B); 7 of these cell lines most closely resembled the molecular phenotypes (BS and N, Table 1) associated with lowest OS [21]. Five of 7 RTKs involved in significant ligand co-occurrence are in group 1, MST1R is in group 2 and $K D R$ in group 3, and 6 of 7 RTKs (excepting PDGFRA) are targeted by cabozantinib. Most RTK/ligand pairs were associated with lower median OS and DFS values relative to unaltered cases, but did not meet a 5\% significance threshold by log-rank test (Supplement Table S2F, center column). The notable exception was the group 2 MST1R/MST1 pair, for which KaplanMeier analysis displayed a trend of improved survival relative to unaltered cases (Supplement Table S2F, center column). Combined, cases harboring groups 1 and 3 RTK/ligand co-alterations had worse OS and DFS relative to unaltered cases with log-rank p values approaching 5\%, but exceeded this threshold only for DFS (18.00 vs. 43.96 mos., $\mathrm{p}=0.0101$ ) for expression $\mathrm{z}>2.0$ and/or gene amplification and/or RTK gene mutation of unclassified pathogenic consequence (Table 2B).

Many TK pathways induce epithelial-to-mesenchymal transition (EMT), which is thought to be a critical process in promoting tumor invasiveness and metastasis. Additional indirect evidence of TK pathway activation and oncogenic signaling in BCa was obtained by interrogating the TCGA dataset [21] for coincident overexpression of TKs and EMT transcriptional activators (TAs) and by measuring TA mRNA copy number in the 15 BCa cell lines identified above. Heat map analysis of TCGA and cell line data revealed a pattern of higher expression for 9 EMT TAs (MYC, RUNX2, SNAI1, SNAI2, SOX2, SOX9, TWIST1, ZEB1 and ZEB2) among molecular phenotypes with lower survival, consistent with oncogenic impact (Fig. 4C). Potentially oncogenic alterations ( $>2$-fold mRNA overexpression and/or gene amplification) in these EMT TAs occurred at a combined rate of 174/408 TCGA samples (43\%) and significant co-occurrence rate of 14\% (Table 3). Median OS for those 14\% harboring EMT TA co-occurrence was significantly lower than for unaltered cases (27.43 vs. 44.91 mos., $\mathrm{p}=0.0175$ ). Potentially oncogenic alterations co-occurred significantly for 
22 (71\%) group 1 TKs and 7 EMT TAs; 9 of these 38 concurrent alterations (24\%) were associated with significantly lower OS and/or progression-free survival (PFS) relative to unaltered cases (Table 4A). In contrast, potentially oncogenic alterations co-occurred among only 5 (24\%) group 2 TKs and 5 EMT TAs, none of which were associated with diminished survival (Table 4B).

\section{Autocrine AXL, CSF1R and MST1R Signaling in BCa Cell Lines}

Potential autocrine signaling by $A X L, C S F 1 R$ and MST1R pathways in BCa cell lines was further investigated using exogenous ligand to induce activation, using cabozantinib to block RTK activation, and using short interfering RNAs (siRNAs) to suppress expression of GAS6 in J82 cells, and MST1 and CSF1 in FL3 cells (Fig. 5). Axl kinase activation (observed as autophosphorylation) normalized to total Axl protein (pAxl/tAxl), was stimulated $>2$-fold by exogenous Gas6 added to intact serum-deprived J82 cells, and this was suppressed significantly below control levels by added cabozantinib (Fig. 5A, left). Consistent with autocrine signaling by endogenous Gas6 production (Fig. 4B, middle), J82 cells transfected with siGAS6 also showed significant pAxl/tAxl suppression relative to control siRNA transfected cells (Fig. 5A, right). The same pattern of significant exogenous Gas6-induced activation, suppression below baseline by cabozantinib, and siGAS6-associated baseline suppression, was observed for the downstream effectors Akt (Fig. 5B) and Erk (Fig. 5C). These results indicate receptor proximal pathway functionality and support the presence of autocrine signaling. This approach was also used to interrogate the receptor proximal pathways for MST1R and CSF1R in FL3 cells (Fig. 5D-F). These pathways were activated by exogenously added ligand and suppressed significantly below baseline by siRNAs directed against their cognate ligands or by cabozantinib, supporting the presence of autocrine proximal pathway activation in these cells.

Gas6-, MST1-, and CSF1-induced migration of J82 and FL3 cells, respectively, was also repressed by cabozantinib treatment (Fig. 6A, B). siRNA suppression of $A X L$ (Fig. 6A, inset) significantly reduced J82 cell migration below the level of untreated serum-deprived cells (Fig. $6 \mathrm{~A}$ ), indicating that autocrine Gas6/Axl signaling contributed to the migration of otherwise untreated J82 cells. In FL3 cells, comparable manipulation of the MST1 and CSF1 pathways using exogenous ligand, cabozantinib and RTK-directed siRNA also indicated autocrine driven migration in otherwise untreated cells (Fig. 6B). Exogenously added Gas6 significantly increased 5637 and J82 cell proliferation rates, and cabozantinib treatment significantly inhibited proliferation by 
these lines below the rate of untreated cells, in the presence or absence of added Gas6 (Fig. 6C). In FL3 cells, added MST1 alone significantly increased proliferation rate, and cabozantinib treatment alone significantly reduced proliferation rate, relative to untreated cells (Fig. 6D). But unlike Gas6driven proliferation in 5637 and J82 cells, treatment with both cabozantinib and MST1 reduced FL3 proliferation to the control cell growth rate, but not below (Fig. 6D). Autocrine-driven proliferation by the $A X L, M S T 1 R$ and CSF1R pathways in J82 and FL3 cells was further supported by studies in which siRNA suppression of ligands or RTKs (Fig. 7A) was exerted in the presence or absence of exogenous ligand and/or cabozantinib (Fig. 7B-D). Consistent with the results of biochemical and cell migration studies, J82 cells transfected with siRNA directed against GAS6 or $A X L$ showed significantly reduced proliferation relative to control siRNA transfected cells (Fig. 7B), as did FL3 cells transfected with siRNA directed against MST1, MST1R, CSF1, or CSF1R (Fig. 7C, D). Anchorage independent growth by J82 (Fig. 7E) and FL3 (Fig. 7F) was similarly enhanced significantly by added ligand, inhibited by cabozantinib treatment, and suppressed by RTKdirected siRNA.

\section{Phenotypic Changes in J82 Cells upon Serial Xenograft Passage in Mice}

Mouse xenograft studies were conducted to further characterize the oncogenic impact of Gas6/Axl autocrine signaling in J82 cells. Tumorigenesis was slow and tumor volumes varied widely relative to many well-studied tumor cell lines from other cancers, to an extent that drug efficacy studies were impractical. Hypothesizing that Gas6/Axl autocrine signaling in tumor xenografts might over time lead to a more aggressive tumor phenotype, 15 mice were implanted with $10^{6}$ cells each; when tumors reached $300 \mathrm{~mm}^{3}$ they were excised, and tumor fragments were serially passaged in mice for 3 x 50-day tumor re-growth cycles. Although some later-cycle individual J82-derived tumors grew faster than others as measured by volume, these were frequently hemorrhagic and necrotic. Tumor tissue samples were taken at each cycle and 14 new cell lines were derived from tumor explants. None of these cell lines formed tumors faster than J82: the growth profiles of 10 J82 tumors (Fig. 8A, left) and 10 tumors from a representative J82 tumor derived cell line (MDXC1, Fig. 8A, center) showed wide variability yet similar mean growth rates (Fig. 8A, right). Quantitative RT-PCR analysis of 8 tumor xenograft-derived cell lines showed that none had lost expression of either GAS6 or AXL; in fact, 6 of 8 had acquired significantly increased expression of MERTK (also activated by Gas6) and KDR (Fig. 8B). Consistent with high 
MERTK transcript levels, MERTK protein abundance in MDXC1 cells was several-fold higher than that of J82 (Fig. 8C). Exogenous Gas6 stimulated robust MERTK autophosphorylation, and the MERTK inhibitor TP0903 reduced phospho-MERTK content below that of untreated serumdeprived cells, suggestive of autocrine Gas6/MERTK activation (Fig. 8C). J82 and MDXC1 cells grew at similar rates in 2D culture, but MDXC1 was notably less motile than J82, at rest or with Gas6 stimulation (Fig. 8D).

Although persistent $A X L / G A S 6$ co-overexpression and acquired MERTK and KDR overexpression did not accelerate tumor xenograft growth rate, other concurrent phenotypic changes might nonetheless bear on disease progression. Seeking an overview of such changes, we used the Nanostring PanCancer Progression panel to analyze mRNA expression in J82 and MDXC1. Of the 770 genes in this panel (identified in Supplement Table S4A), 321 were expressed at significantly different levels in MDXC1 relative to J82 (Qlucore 2-group comparison $\mathrm{p}=0.021, \mathrm{q}=$ 0.05; Fig. 8E; Supplement Table S4B). Ingenuity Pathway Analysis [36] of the 321 genes revealed that the top significantly matched Diseases and Bio-functions included several categories of cell migration, cell death and cell proliferation. Consistent with experimental observations, the zscores indicated inactivated migration and proliferation in MDXC1 relative to J82 and activated cell death in MDXC1 relative to J82 (Supplement Table S5A). Other notable findings in the IPA analysis were consistent with a transition from inflammatory AXL signaling to tolerogenic MERTK signaling, as described previously by Zagorska et al. [44]. MDXC1 expression of several proinflammatory mediators (e.g. CXCL8, IL1A, IL1B, IL11, IL6, IL18, and PLAU, Table S4B) was significantly diminished while negative regulators of inflammation were significantly increased (e.g. SPARC, TGF- $\beta 1$ ) relative to J82, and top IPA predicted Upstream Regulators that MDXC1 acquired were transforming growth factor beta-1, estradiol and dexamethasone (Supplement Table S5B), the latter a known inducer of MERTK expression [44]. Top IPA predicted Canonical Pathways were also consistent with this phenotypic transition (Supplement Table S5C). 


\section{Discussion}

Among several important discoveries, the comprehensive molecular analyses of $\mathrm{BCa}$ patient tumor samples published to date divided profound tumor heterogeneity into distinct phenotypes [13-21]. Although these broad classes display only a few dominant oncogenic pathways recognized in other cancers, they facilitate a process of systematic refinement of molecular pathogenesis that, for BCa in particular, is challenged with proving the criticality of less frequent, more complex and potentially transient processes driving disease progression. Accordingly, our focus was averted from well-studied oncogenic protein TK alterations, such as those affecting fibroblast growth factor receptors [11-13, 20,43], and directed toward alterations that are as yet only circumstantially implicated in malignancy, with the goals of using TK inhibitors to their best therapeutic advantage and identifying new TK pathways for further study. We surveyed data obtained from 408 MIBC tumor samples previously classified into broad molecular phenotypes with distinct median overall survival periods (N, BS, L, LI and LP; [21]) for potentially oncogenic TK alterations, such as amplification and overexpression that might underlie catalytic overactivity, and for coincident overexpression of receptor TKs and their cognate ligands. Prompted by the positive results of a clinical trial of cabozantinib in patients with advanced or metastatic BCa [22], we further focused on RTKs targeted by this multikinase inhibitor for aberrant features and phenotypic distribution.

The expression profiles of 89 TKs analyzed across N, BS, L, LI and LP phenotypes fell into 3 broad groups: 2 with reciprocal patterns of overexpression among poorer surviving $\mathrm{N}$ and BS phenotypes and the best surviving LP phenotype (TK groups 1 and 2, respectively), and a group of 37 TKs with expression patterns that were independent of molecular phenotype (TK group 3). The significant differential distribution of group 1 and 2 TKs across phenotypes indicates that among the $>3000$ genes used to develop the phenotypes [21], these 52 TKs were defining elements, which in turn implies possible functional contributions to clinical distinctions, including survival. Although the combined incidence of potentially oncogenic mRNA overexpression and/or gene amplification events in all 3 groups were similar, significant co-occurrence of these alterations was disproportionately higher in group 1, in both number of samples affected and fraction of TK pairings. OS and PFS for patients harboring these alterations in group 1 TKs were significantly worse than for those without alterations, consistent with the reported relatively poor survival of $\mathrm{N}$ 
and BS phenotypes [21]. In contrast, patients with the same alterations in group 2 TKs had significantly better OS and DFS than the unaltered group, again consistent with more frequent occurrence in the better surviving L and LP phenotypes [21]. Patients harboring overexpression and/or amplification of group 3 TKs also showed significantly diminished DFS relative to those without alteration. These findings reinforce the likelihood that among all TKs, overexpression and/or amplification of groups 1 and 3 TKs contribute disproportionately to BCa progression.

The most recent Cabometyx ${ }^{\mathrm{TM}}$ (cabozantinib) prescribing information available from the US Food and Drug Administration [33] identifies AXL, FLT1, FLT3, FLT4, KDR, KIT, MET, MERTK, NTRK2, RET, ROS1, TYRO3 and TEK as its targets. We found that cabozantinib inhibited these RTKs in vitro with IC $_{50}$ values $<50 \mathrm{nM}$, with the exception of KIT (IC $50143 \mathrm{nM}$ ), FLT1 (IC 333 nM) and TEK (not included in our assays). Yakes et al. [28] reported potent TEK inhibition in vitro (IC $_{50}$ $14 \mathrm{nM}$ ), but less potent MST1R inhibition than we observed (IC $50124 \mathrm{nM}$ vs. $42 \mathrm{nM}$ ). Niehus et al. [32] reported complete inhibition of CSF1R activation in intact cells, consistent with potent inhibition we observed in vitro $\left(\mathrm{IC}_{50} 14 \mathrm{nM}\right)$. In addition to these 16 targets, we observed potent inhibition of 3 other RTKs in vitro: DDR1, DDR2 and NTRK3, with IC 50 values of 11, 0.5, 20 and 3 $\mathrm{nM}$, respectively.

Combined, these 19 ctRTKs were overexpressed and/or amplified in most (69\%) MIBC cases in the TCGA dataset analyzed by Robertson et al. [21], with individual alteration frequencies from $4 \%$ to $20 \%$. Co-occurring alterations were also frequent (150 events). Sixteen ctRTKs were in TK groups 1 and 3, whose combined alterations occurred disproportionately in patients with diminished survival relative to those without alteration; indeed, the patient cohort harboring alterations in 14 ctRTKs (all except DDR1, FLT1/4, KIT and MST1R; 46\% of cases) had significantly worse OS and DFS than those without alterations. The combination of wide target spectrum and high frequency of target alteration implicated in worse outcome is consistent with the relatively high overall response rate (33\%) observed in our clinical trial of cabozantinib in advanced BCa patents [22]. However, wide target spectrum also poses serious challenges to developing diagnostic biomarker panels and learning the molecular pathogenesis underlying individual patient responses. Anticipating that BCa-derived cell lines would be invaluable in that process, a preliminary characterization of how their TK expression profiles resembled those of TCGA samples was performed to help optimize their use in assessing the criticality of specific TK profiles in oncogenically relevant bioactivities. 
We determined mRNA copy number for 31 TKs in 15 BCa-derived cell lines; this TK set represented groups 1 and 2 as defined using TCGA samples and retained the same significant differential distribution across LP vs. $(\mathrm{LI}+\mathrm{L})$ vs. $(B S+N)$ phenotypes. A simple method was used to classify these cell lines among these molecular phenotypes on the basis of TK expression profile alone. We noted that several features discussed below, such as concurrent overexpression of RTK/cognate ligand pairs, and/or EMT transcriptional activators, occurred more frequently in cell lines classified as $\mathrm{N}$ or BS, corresponding to patient groups with worse survival relative those of other phenotypes. The classifications helped in selecting cell lines for studies of autocrine signaling, but may have more general utility, e.g. in determining the effects of multikinase inhibitors when specific combinations of active target pathways are present. Classification may also help to integrate kinomic with other -omic analyses to better inform cell line selection for studies aimed at specific BCa patient cohorts.

Prevalent mechanisms of oncogenic TK activation (i.e. gene amplification, chromosomal rearrangements, gain of function mutations, and autocrine activation or aberrant ligand production in the tumor microenvironment) suppress immune surveillance and enhance tumor cell survival, proliferation, motility and invasion in a wide spectrum of cancers and thereby drive tumor progression, metastasis and drug resistance [37-39]. Among these mechanisms, autocrine activation and aberrant ligand production in the tumor microenvironment may appear as coexpression in RNA Seq analysis of tumor samples and occur with relatively low incidence. Both are, nonetheless, capable disease drivers and drug resistance pathways.

We found significant co-occurrence of mRNA overexpression ( $>2$-fold RNASeq V2 z-scores) and/or gene amplification of $A X L, C S F 1 R, D D R 2, K D R, M S T 1 R, P D G F R A$ and TEK and their cognate ligands among 65/408 cases (16\%) in the BCa TCGA dataset [21]. These findings indicate that oncogenic autocrine RTK signaling could have occurred and provide impetus to fully determine its extent and criticality in BCa. RTK/ligand co-expression was confirmed by immunoblot analysis of CSF1R/CSF1, AXL/GAS6, and MST1R/MST1 in 9 BCa cell lines, reinforcing the hypothesis that autocrine signaling occurs in BCa patients. Six co-altered RTK/ligand pathways found are targeted by cabozantinib, and cabozantinib suppressed proliferation, motility and anchorage independent growth below basal levels in BCa cell lines harboring these alterations. All but 2 RTK/ligand pairs (KDR/VEGFA and MST1R/MST1) affected group 1 TK pathways that were frequently altered in the lower survival of $\mathrm{N}$ and BS phenotypes. Each co-alteration was manifested in $<3 \%$ of cases, so 
although median OS and DFS values of patients harboring these events were below those of unaltered cases, they were not so extreme as to meet a $5 \%$ significance threshold. The fact that log-rank p values approached that threshold when group 1 cases were combined supports the possibility that these events were clinically relevant. Median OS and DFS values of patients harboring the group 2 MST1R/MST1 co-alteration, in contrast, segregated with the more favorable survival of the L and LP phenotypes. Whether this co-alteration has lower oncogenic potential than group 1 RTK/ligand pairs, or other features in the L and LP phenotypes offset its impact, remains to be determined.

Epithelial-to-mesenchymal transition (EMT) often precedes, and in model systems has been shown to promote, tumor invasiveness and metastasis [40]. Concurrent overexpression of TKs and a set of EMT TAs that they regulate was used as a proxy of oncogenic TK pathway activation in samples from the BCa TCGA dataset [21]. We also measured TA mRNA copy number in the 15 BCa-derived cell lines used for RTK analysis. Heat map analysis of TCGA and cell line data revealed a clear pattern of higher expression for MYC, RUNX2, SNAI1, SNAI2, SOX2, SOX9, TWIST1, $Z E B 1$ and ZEB2 which strongly resembled the pattern of group $1 \mathrm{TKs}$, consistent with oncogenic impact. Indeed, co-occurring alterations among group 1 TKs and EMT TAs were 3-fold more frequent than for group 2 TKs, and 24\% of those were associated with significantly lower OS and/or PFS relative to unaltered cases. mRNA overexpression and/or gene amplification among these EMT TAs occurred in a combined 174 (43\%) TCGA samples, 59 (34\%) of which had significantly co-occurring EMT TA alterations. OS for patients with co-occurring EMT TA alterations was 27.43 mos. vs. 44.91 mos. for those without alterations $(\mathrm{p}=0.0175)$. The possibility that co-occurring alterations of RTK/ligand pairs or TKs and EMT TAs detected in tumor/liquid biopsies, plasma DNA or exosomes from BCa patients might predict clinical outcome warrants further study.

Direct evidence of autocrine signaling by AXL, CSF1R and MST1R pathways was found in several BCa-derived cell lines. Selective siRNAs directed against ligand or RTK suppressed receptor and canonical downstream mediator activation, as well as cell proliferation, migration and anchorage-independent growth, below basal levels. The results obtained using selective siRNAs support the concept that significantly reduced basal levels of the same biochemical proxies and biological activities by cabozantinib in these cell lines also occurred by blocking autocrine RTK signaling, and suggest that this mechanism of action underlies a portion of the efficacy we 
observed in BCa patients on a phase II cabozantinib clinical trial [22], and may be an important disease driver in BCa. While this manuscript was in preparation, another independent report [45] found evidence of GAS6 expression in BCa tissue samples associated with lower survival, and functional impact of GAS6 signaling in 5 BCa-derived cell lines; those findings reinforce the likelihood that autocrine AXL signaling contributes to BCa disease progression in a subset of patients.

Serial passage of the human BCa-derived cell line J82 as tumor xenografts in mice generated several J82-derived cell lines. One such line, MDXC1 grew comparably to J82 in 2D culture, but was less motile and displayed significant expression changes in cancer related genes. Notably, none of the J82 xenograft-derived cell lines analyzed had lost expression of either GAS6 or $A X L$, suggesting that retention of this activated pathway contributed to tumorigenicity. Six of 8 derived cell lines acquired significantly higher expression of MERTK and KDR, and MDXC1 cells showed evidence of robust MERTK activation. Ingenuity Pathway Analysis [36] of 321 differentially expressed genes in the Nanostring PanCancer Progression 770 gene panel revealed that in MDXC1, genes comprising cell migration and cell proliferation bio-functions were predominantly inactivated, while those comprising cell death were activated. Accompanying this were significant changes in regulators of inflammation that were consistent with a shift from AXL to MERTK signaling, which have been distinguished in carefully controlled studies [44] that enlighten earlier work on TAM receptor signaling in tumor immune surveillance [38, 41]. Indeed, recent studies show that MERTK signaling contributes to an immunosuppressive environment by inducing an anti-inflammatory cytokine profile and regulating checkpoint inhibitor signaling in hematopoietic and solid tumors [46-48]. Our xenograft studies in immunocompromised SCID/Beige mice would be unlikely to display these changes as a pro-tumorigenic transition from J82 to MDXC1. In humans, however, such a transition might lead to more effective tumor evasion of immune recognition and disease progression, despite increased tumor cell death and neoantigen abundance. We recently reported that in patients with advanced BCa, cabozantinib treatment modulated immune checkpoint regulators PD-1 and TIM-3, increased anti-tumor monocytes, and decreased pro-tumorigenic monocytes and myeloid-derived suppressor cell (MDSC) populations; a greater-than-median decrease in the granulocytic MDSC population was significantly associated with a favorable outcome [22]. While our focus here was on coincident overexpression or amplification of GAS6, AXL and MERTK as proxies of putative driver roles and 
bioRxiv preprint doi: https://doi.org/10.1101/2020.10.15.341206; this version posted October 15, 2020. The copyright holder for this preprint (which was not certified by peer review) is the author/funder. This article is a US Government work. It is not subject to copyright under 17 USC 105 and is also made available for use under a CCO license.

relevant cabozantinib targets, our findings also suggest that a more comprehensive characterization of these pathways as drivers in tumor and immune compartments should inform efforts to optimally combine TKIs and checkpoint inhibitors for BCa treatment. 
bioRxiv preprint doi: https://doi.org/10.1101/2020.10.15.341206; this version posted October 15, 2020. The copyright holder for this preprint

(which was not certified by peer review) is the author/funder. This article is a US Government work. It is not subject to copyright under 17 USC 105 and is also made available for use under a CCO license.

\section{Acknowledgments}

This work was supported by the Intramural Research Program of the NIH, National Cancer Institute, Center for Cancer Research. 


\section{References}

[1] Bray F, Ferlay J, Soerjomataram I, Siegel RL, Torre LA, Jemal A. Global Cancer Statistics 2018: GLOBOCAN Estimates of Incidence and Mortality Worldwide for 36 Cancers in 185 Countries. CA CANCER J CLIN 2018;68:394-424.

[2] Howlader N, Noone AM, Krapcho M, Miller D, Brest A, Yu M, Ruhl J, Tatalovich Z, Mariotto A, Lewis DR, Chen HS, Feuer EJ, Cronin KA (eds). SEER Cancer Statistics Review, 1975-2017, National Cancer Institute. Bethesda, MD, https://seer.cancer.gov/csr/1975_2017/, based on November 2019 SEER data submission, posted to the SEER web site, April 2020.

[3] von der Maase H, Sengelov L, Roberts JT, Ricci S, Dogliotti L, Oliver T, Moore MJ, Zimmermann A, Arning M. Long-term survival results of a randomized trial comparing gemcitabine plus cisplatin, with methotrexate, vinblastine, doxorubicin, plus cisplatin in patients with bladder cancer. J Clin Oncol 2005; 23: 4602-8.

[4] De Santis M, Bellmunt J, Mead G, Kerst JM, Leahy M, Maroto P, Gil T, Marreaud S, Daugaard G, Skoneczna I, Collette S, Lorent J, de Wit R, Sylvester R. Randomized phase II/III trial assessing gemcitabine/carboplatin and methotrexate/carboplatin/vinblastine in patients with advanced urothelial cancer who are unfit for cisplatin-based chemotherapy: EORTC study 30986. J Clin Oncol 2012; 30: 191-9.

[5] Rosenberg JE, Hoffman-Censits J, Powles T, van der Heijden MS, Balar AV, Necchi A, Dawson N, O'Donnell PH, Balmanoukian A, Loriot Y, Srinivas S, Retz MM, Grivas P, Joseph RW, Galsky MD, Fleming MT, Petrylak DP, Perez-Gracia JL, Burris HA, Castellano D, Canil C, Bellmunt J, Bajorin D, Nickles D, Bourgon R, Frampton GM, Cui N, Mariathasan S, Abidoye O, Fine GD, Dreicer R. Atezolizumab in patients with locally advanced and metastatic urothelial carcinoma who have progressed following treatment with platinum-based chemotherapy: a single-arm, multicentre, phase 2 trial. Lancet 2016; 387: 1909-20. 
[6] Sharma P, Retz M, Siefker-Radtke A, Baron A, Necchi A, Bedke J, Plimack ER, Vaena D, Grimm MO, Bracarda S, Arranz JÁ, Pal S, Ohyama C, Saci A, Qu X, Lambert A, Krishnan S, Azrilevich A, Galsky MD. Nivolumab in metastatic urothelial carcinoma after platinum therapy (CheckMate 275): a multicentre, single-arm, phase 2 trial. Lancet Oncol 2017; 18: 312-22.

[7] Bellmunt J, de Wit R, Vaughn DJ, Fradet Y, Lee JL, Fong L, Vogelzang NJ, Climent MA, Petrylak DP, Choueiri TK, Necchi A, Gerritsen W, Gurney H, Quinn DI, Culine S, Sternberg CN, Mai Y, Poehlein CH, Perini RF, Bajorin DF; KEYNOTE-045 Investigators. Pembrolizumab as SecondLine Therapy for Advanced Urothelial Carcinoma. N Engl J Med 2017; 376: 1015-26.

[8] Apolo AB, Infante JR, Balmanoukian A, Patel MR, Wang D, Kelly K, Mega AE, Britten CD, Ravaud A, Mita AC, Safran H, Stinchcombe TE, Srdanov M, Gelb AB, Schlichting M, Chin K, Gulley JL. Avelumab, an Anti-Programmed Death- Ligand 1 Antibody, In Patients With Refractory Metastatic Urothelial Carcinoma: Results From a Multicenter, Phase Ib Study. J Clin Oncol 2017; 35: 2117-24.

[9] Balar AV, Galsky MD, Rosenberg JE, Powles T, Petrylak DP, Bellmunt J, Loriot Y, Necchi A, Hoffman-Censits J, Perez-Gracia JL, Dawson NA, van der Heijden MS, Dreicer R, Srinivas S, Retz MM, Joseph RW, Drakaki A, Vaishampayan UN, Sridhar SS, Quinn DI, Durán I, Shaffer DR, Eigl BJ, Grivas PD, Yu EY, Li S, Kadel EE 3rd, Boyd Z, Bourgon R, Hegde PS, Mariathasan S, Thåström A, Abidoye 00, Fine GD, Bajorin DF; IMvigor210 Study Group. Atezolizumab as first-line treatment in cisplatin-ineligible patients with locally advanced and metastatic urothelial carcinoma: a singlearm, multicentre, phase 2 trial. Lancet 2017; 389: 67-76.

[10] Balar AV, Castellano D, O'Donnell PH, Grivas P, Vuky J, Powles T, Plimack ER, Hahn NM, de Wit R, Pang L, Savage MJ, Perini RF, Keefe SM, Bajorin D, Bellmunt J. First-line pembrolizumab in cisplatinineligible patients with locally advanced and unresectable or metastatic urothelial cancer (KEYNOTE-052): a multicentre, single-arm, phase 2 study. Lancet Oncol 2017; 18 : 1483-92. 
[11] Siefker-Radtke A, Necchi A, Park S, Garcia-Donas J, Huddart RA, Burgess EF, Fleming MT, Rezazadeh A, Mellado B, Varlamov S, Joshi M, Duran I, Tagawa ST, OHagan A, Avadhani AN, Zhong B, De Porre P, Loriot, Y. First results from the primary analysis population of the phase 2 study of erdafitinib (ERDA; JNJ-42756493) in patients (pts) with metastatic or unresectable urothelial carcinoma (mUC) and FGFR alterations (FGFRalt). J Clin Oncol 2018; 36(15 suppl): abstr 4503.

[12] Rosenberg JE, O'Donnell PH, Balar AV, McGregor BA, Heath EI, Yu EY, Galsky MD, Hahn NM, Gartner EM, Pinelli JM, Liang SY, Melhem-Bertrandt A, Petrylak DP. Pivotal Trial of Enfortumab Vedotin in Urothelial Carcinoma After Platinum and Anti-Programmed Death 1/Programmed Death Ligand 1 Therapy. J Clin Oncol 2019; 37: 2592-600.

[13] Iyer G, Al-Ahmadie H, Schultz N, Hanrahan AJ, Ostrovnaya I, Balar AV, Kim PH, Lin O, Weinhold N, Sander C, Zabor EC, Janakiraman M, Garcia-Grossman IR, Heguy A, Viale A, Bochner BH, Reuter VE, Bajorin DF, Milowsky MI, Taylor BS, Solit DB. Prevalence and cooccurrence of actionable genomic alterations in high-grade bladder cancer. J Clin Oncol. 2013;31(25):3133-3140.

[14] Guo G, Sun X, Chen C, Wu S, Huang P, Li Z, Dean M, Huang Y, Jia W, Zhou Q, Tang A, Yang Z, Li X, Song P, Zhao X, Ye R, Zhang S, Lin Z, Qi M, Wan S, Xie L, Fan F, Nickerson ML, Zou X, Hu X, Xing L, Lv Z, Mei H, Gao S, Liang C, Gao Z, Lu J, Yu Y, Liu C, Li L, Fang X, Jiang Z, Yang J, Li C, Zhao X, Chen J, Zhang F, Lai Y, Lin Z, Zhou F, Chen H, Chan HC, Tsang S, Theodorescu D, Li Y, Zhang X, Wang J, Yang H, Gui Y, Wang J, Cai Z. Whole-genome and whole-exome sequencing of bladder cancer identifies frequent alterations in genes involved in sister chromatid cohesion and segregation. Nat Genet. 2013;45(12):1459-1463.

[15] Van Allen EM, Mouw KW, Kim P, Iyer G, Wagle N, Al-Ahmadie H, Zhu C, Ostrovnaya I, Kryukov GV, O'Connor KW, Sfakianos J, Garcia-Grossman I, Kim J, Guancial EA, Bambury R, Bahl S, Gupta N, Farlow D, Qu A, Signoretti S, Barletta JA, Reuter V, Boehm J, Lawrence M, Getz G, Kantoff P, Bochner BH, Choueiri TK, Bajorin DF, Solit DB, Gabriel S, D'Andrea A, Garraway LA, Rosenberg JE. Somatic ERCC2 mutations correlate with cisplatin sensitivity in muscle- 
invasive urothelial carcinoma. Cancer Discov. 2014;4(10):1140-

[16] Cancer Genome Atlas Research Network. Comprehensive molecular characterization of urothelial bladder carcinoma. Nature. 2014;507(7492):315-322.

[17] Kim PH, Cha EK, Sfakianos JP, Iyer G, Zabor EC, Scott SN, Ostrovnaya I, Ramirez R, Sun A, Shah R, Yee AM, Reuter VE, Bajorin DF, Rosenberg JE, Schultz N, Berger MF, Al-Ahmadie HA, Solit DB, Bochner BH. Genomic predictors of survival in patients with high-grade urothelial carcinoma of the bladder. Eur Urol. 2015;67(2):198-201.

[18] Kim PH, Cha EK, Sfakianos JP, Iyer G, Zabor EC, Scott SN, Ostrovnaya I, Ramirez R, Sun A, Shah R, Yee AM, Reuter VE, Bajorin DF, Rosenberg JE, Schultz N, Berger MF, Al-Ahmadie HA, Solit DB, Bochner BH. Frequent somatic CDH1 loss-of-function mutations in plasmacytoid variant bladder cancer. Nat Genet. 2016;48(4):356-358.

[19] Faltas BM, Prandi D, Tagawa ST, Molina AM, Nanus DM, Sternberg C, Rosenberg J, Mosquera JM, Robinson B, Elemento O, Sboner A, Beltran H, Demichelis F, Rubin MA. Clonal evolution of chemotherapy-resistant urothelial carcinoma. Nat Genet. 2016;48(12):1490-1499.

[20] Pietzak EJ, Bagrodia A, Cha EK, Drill EN, Iyer G, Isharwal S, Ostrovnaya I, Baez P, Li Q, Berger MF, Zehir A, Schultz N, Rosenberg JE, Bajorin DF, Dalbagni G, Al-Ahmadie H, Solit DB, Bochner BH. Next-generation Sequencing of Nonmuscle Invasive Bladder Cancer Reveals Potential Biomarkers and Rational Therapeutic Targets. Eur Urol. 2017;72(6):952-959.

[21] Robertson AG, Kim J, Al-Ahmadie H, Bellmunt J, Guo G, Cherniack AD, Hinoue T, Laird PW, Hoadley KA, Akbani R, Castro MAA, Gibb EA, Kanchi RS, Gordenin DA, Shukla SA, SanchezVega F, Hansel DE, Czerniak BA, Reuter VE, Su X, de Sa Carvalho B, Chagas VS, Mungall KL, Sadeghi S, Pedamallu CS, Lu Y, Klimczak LJ, Zhang J, Choo C, Ojesina AI, Bullman S, Leraas KM, Lichtenberg TM, Wu CJ, Schultz N, Getz G, Meyerson M, Mills GB, McConkey DJ; TCGA Research Network, Weinstein JN, Kwiatkowski DJ, Lerner SP. Comprehensive Molecular 
Characterization of Muscle-Invasive Bladder Cancer [published correction appears in Cell. 2018 Aug 9;174(4):1033]. Cell. 2017;171(3):540-556.e25.

[22] Apolo AB, Nadal R, Tomita Y, Davarpanah NN, Cordes LM, Steinberg SM, Cao L, Parnes HL, Costello R, Merino MJ, Folio L, Lindenberg L, Raffeld M, Lin J, Lee M-J, Lee S, Alarcon SV, Yuno A, Dawson N, Allette K, Roy A, De Silva D, Lee MM, Sissung TM, Figg WD, Agarwal PK, Wright JJ, Ning YM, Gulley JL, Dahut WL, Bottaro DP, Trepel JB. Cabozantinib and peripheral immunity in advanced urothelial carcinoma: Final results from an open-label, phase II trial. Lancet Oncology. 2020 (In Press).

[23] Lee YH, Apolo AB, Agarwal PK, Bottaro DP. Characterization of HGF/Met Signaling in Cell Lines Derived From Urothelial Carcinoma of the Bladder. Cancers. 2014;6:2313-2329.

[24] Tate JG, Bamford S, Jubb HC, Sondka Z, Beare DM, Bindal N, Boutselakis H, Cole CG, Creatore C, Dawson E, Fish P, Harsha B, Hathaway C, Jupe SC, Kok CY, Noble K, Ponting L, Ramshaw CC, Rye CE, Speedy HE, Stefancsik R, Thompson SL, Wang S, Ward S, Campbell PJ, Forbes SA. COSMIC: the Catalogue Of Somatic Mutations In Cancer. Nucleic Acids Res. 2019;47(D1):D941-D947.

[25] Wang X, Wang S, Lin F, Zhang Q, Chen H, Wang X, Wen C, Ma J, Hu L. Pharmacokinetics and tissue distribution model of cabozantinib in rat determined by UPLC-MS/MS. J Chromatogr B Analyt Technol Biomed Life Sci. 2015;983-984:125-131.

[26] Song EK, Tai WM, Messersmith WA, Bagby S, Purkey A, Quackenbush KS, Pitts TM, Wang G, Blatchford P, Yahn R, Kaplan J, Tan AC, Atreya CE, Eckhardt G, Kelley RK, Venook A, Kwak EL, Ryan D, Arcaroli JJ. Potent antitumor activity of cabozantinib, a c-MET and VEGFR2 inhibitor, in a colorectal cancer patient-derived tumor explant model. Int J Cancer. 2015;136(8):19671975.

[27] Hart CD, De Boer RH. Profile of cabozantinib and its potential in the treatment of advanced medullary thyroid cancer. Onco Targets Ther. 2013;6:1-7. 
[28] Yakes FM, Chen J, Tan J, Yamaguchi K, Shi Y, Yu P, Qian F, Chu F, Bentzien F, Cancilla B, Orf J, You A, Laird AD, Engst S, Lee L, Lesch J, Chou YC, Joly AH. Cabozantinib (XL184), a novel MET and VEGFR2 inhibitor, simultaneously suppresses metastasis, angiogenesis, and tumor growth. Mol Cancer Ther. 2011;10(12):2298-2308.

[29] Katayama R, Kobayashi Y, Friboulet L, Lockerman EL, Koike S, Shaw AT, Engelman JA, Fujita N. Cabozantinib overcomes crizotinib resistance in ROS1 fusion-positive cancer. Clin Cancer Res. 2015;21(1):166-174. doi:10.1158/1078-0432.CCR-14-1385.

[30] Cabanillas ME, Brose MS, Holland J, Ferguson KC, Sherman SI. A phase I study of cabozantinib (XL184) in patients with differentiated thyroid cancer. Thyroid. 2014;24(10):1508-1514.

[31] Fuse MJ, Okada K, Oh-Hara T, Ogura H, Fujita N, Katayama R. Mechanisms of Resistance to NTRK Inhibitors and Therapeutic Strategies in NTRK1-Rearranged Cancers. Mol Cancer Ther. 2017;16(10):2130-2143.

[32] Niehus SE, Tran DDH, Mischak M, Koch A. Colony-stimulating factor-1 receptor provides a growth advantage in epithelial cancer cell line A431 in the presence of epidermal growth factor receptor inhibitor gefitinib. Cell Signal. 2018 Nov;51:191-198.

[33] US Food and Drug Administration: https://www.accessdata.fda.gov/drugsatfda_docs/label/2019/208692s003lbl.pdf

[34] Cerami E, Gao J, Dogrusoz U, Gross BE, Sumer SO, Aksoy BA, Jacobsen A, Byrne CJ, Heuer ML, Larsson E, Antipin Y, Reva B, Goldberg AP, Sander C, Schultz N. The cBio cancer genomics portal: an open platform for exploring multidimensional cancer genomics data. Cancer Discov 2012, 2:401-404.

[35] Lee YH, Morrison BL, Bottaro DP. Synergistic signaling of tumor cell invasiveness by hepatocyte growth factor and hypoxia. J Biol Chem. 2014;289(30):20448-20461. 
[36] Krämer A, Green J, Pollard J Jr, Tugendreich S. Causal analysis approaches in Ingenuity Pathway Analysis. Bioinformatics. 2014;30(4):523-530.

[37] Jiang W, Ji M. Receptor tyrosine kinases in PI3K signaling: The therapeutic targets in cancer. Semin Cancer Biol. 2019;59:3-22.

[38] Graham DK, DeRyckere D, Davies KD, Earp HS. The TAM family: phosphatidylserine sensing receptor tyrosine kinases gone awry in cancer. Nat Rev Cancer. 2014;14(12):769-785.

[39] Du Z, Lovly CM. Mechanisms of receptor tyrosine kinase activation in cancer. Mol Cancer. 2018;17(1):58.

[40] Navas T, Kinders RJ, Lawrence SM, Ferry-Galow KV, Borgel S, Hollingshead MG, Srivastava AK, Alcoser SY, Makhlouf HR, Chuaqui R, Wilsker DF, Konaté MM, Miller SB, Voth AR, Chen L, Vilimas T, Subramanian J, Rubinstein L, Kummar S, Chen AP, Bottaro DP, Doroshow JH, Parchment RE. Clinical Evolution of Epithelial-Mesenchymal Transition in Human Carcinomas. Cancer Res. 2020;80(2):304-318.

[41] Rothlin CV, Carrera-Silva EA, Bosurgi L, Ghosh S. TAM receptor signaling in immune homeostasis. Annu Rev Immunol. 2015;33:355-391.

[42] Lemke G. Phosphatidylserine Is the Signal for TAM Receptors and Their Ligands. Trends Biochem Sci. 2017;42(9):738-748.

[43] Helsten T, Elkin S, Arthur E, Tomson BN, Carter J, Kurzrock R. The FGFR Landscape in Cancer: Analysis of 4,853 Tumors by Next-Generation Sequencing. Clin Cancer Res. 2016;22(1):259-267.

[44] Zagórska A, Través PG, Lew ED, Dransfield I, Lemke G. Diversification of TAM receptor tyrosine kinase function. Nat Immunol. 2014;15(10):920-928. 
[45] Mao S, Wu Y, Wang R, Guo Y, Bi D, Ma W, Zhang W, Zhang J, Yan Y, Yao X. Overexpression of GAS6 promotes cell proliferation and invasion in bladder cancer by activation of the PI3K/AKT pathway. OncoTarg Ther. 2020:13 4813-4824.

[46] Huelse J, Fridlyand D, Earp S, DeRyckere D, Graham DK. MERTK in cancer therapy: Targeting the receptor tyrosine kinase in tumor cells and the immune system [published online ahead of print, 2020 May 14]. Pharmacol Ther. 2020;107577.

[47] Lee-Sherick AB, Jacobsen KM, Henry CJ, Huey MG, Parker RE, Page LS, Hill AA, Wang X, Frye SV, Earp HS, Jordan CT, DeRyckere D, Graham DK. MERTK inhibition alters the PD-1 axis and promotes anti-leukemia immunity. JCI Insight. 2018;3(21):e97941.

[48] Caetano MS, Younes AI, Barsoumian HB, Quigley M, Menon H, Gao C, Spires T, Reilly TP, Cadena AP, Cushman TR, Schoenhals JE, Li A, Nguyen QN, Cortez MA, Welsh JW. Triple Therapy with MerTK and PD1 Inhibition Plus Radiotherapy Promotes Abscopal Antitumor Immune Responses. Clin Cancer Res. 2019;25(24):7576-7584. 
bioRxiv preprint doi: https://doi.org/10.1101/2020.10.15.341206; this version posted October 15,2020 . The copyright holder for this preprint (which was not certified by peer review) is the author/funder. This article is a US Government work. It is not subject to copyright under 17 USC 105 and is also made available for use under a CCO license.

Table 1. Classification of BCa-derived cell lines based on TK-specific molecular phenotypes adapted from those defined using TCGA data analyzed by Robertson et al. [21] (all samples with RNASeq V2 data, $n=408$ ). Expression profiles for 31 TKs among TCGA patient samples were significantly correlated with molecular phenotype (neuronal, basal squamous, luminal, luminal infiltrating, and luminal papillary) and $O S\left(p=1.00 \times 10-4, q=8.97 \times 10-5, F_{2,405}>9.42, R^{2}>0.044\right.$ for the 3-group comparison $\mathrm{F}$ test: $\mathrm{LP}$ vs. $(\mathrm{LI}+\mathrm{L})$ vs. (BS $+\mathrm{N})$. Cell line expression profiles for the TKs were compared with the respective TCGA patient tumor TK profiles and assigned to a molecular phenotype if its mean correlation coefficient was distinguished from the respective coefficients for the other phenotypes by t-test at $p<0.05$.

\begin{tabular}{|c|c|c|c|}
\hline Cell line & Closest phenotype & Correlation value & Passed t-test \\
\hline RT4 & Luminal papillary & 0.152 & Yes \\
\hline UMUC5 & Luminal papillary & 0.112 & Yes except Luminal \\
\hline SW780 & Luminal papillary & 0.247 & Yes except Luminal \\
\hline HT1376 & Luminal papillary & 0.298 & Yes except Luminal \\
\hline FL3 & Basal squamous & 0.140 & Yes \\
\hline UMUC3 & Basal squamous & 0.176 & Yes \\
\hline TCCSUP & Basal squamous & 0.134 & No \\
\hline J82 & Basal squamous & 0.101 & Yes \\
\hline T24 & Basal squamous & 0.049 & Yes \\
\hline T24M2 & Luminal infiltrating & 0.035 & No \\
\hline 5637 & Basal squamous & 0.110 & Yes \\
\hline HT1197 & Basal squamous & 0.042 & Yes \\
\hline T24T & Neuronal & 0.197 & No \\
\hline RT112 & Neuronal & 0.107 & No \\
\hline SLT3 & Neuronal & 0.058 & \\
\hline
\end{tabular}


bioRxiv preprint doi: https://doi.org/10.1101/2020.10.15.341206; this version posted October 15,2020 . The copyright holder for this preprint (which was not certified by peer review) is the author/funder. This article is a US Government work. It is not subject to copyright under 17 USC 105 and is also made available for use under a CCO license.

Table 2. (A) Significant co-occurrence of potentially oncogenic alterations (RNASeq V2 $>2$-fold and/or gene amplification) for RTKs and cognate ligands in BCa TCGA dataset analyzed by Robertson et al. $(n=408)$ [21] and differences in median OS and PFS.

\begin{tabular}{|c|c|c|c|c|c|c|c|c|}
\hline \multicolumn{4}{|c|}{ Gene } & \multicolumn{3}{c|}{ Amplification and/or Overexpression } & $\begin{array}{c}\text { Odds Ratio } \\
\text { (Log 2) }\end{array}$ & p-Value \\
\hline TK Group & RTK & Ligand & Neither & RTK & Ligand & Both & & \\
\hline 1 & AXL & GAS6 & 358 & 16 & 23 & 7 & 2.768 & $<0.001$ \\
\hline 1 & CSF1R & CSF1 & 355 & 21 & 17 & 11 & $>3$ & $<0.001$ \\
\hline 1 & DDR2 & COL4A1 & 310 & 62 & 21 & 11 & 1.389 & 0.016 \\
\hline 1 & DDR2 & COL10A1 & 309 & 70 & 15 & 10 & 1.557 & 0.013 \\
\hline 3 & KDR & VEGFA & 340 & 30 & 27 & 7 & 1.555 & 0.026 \\
\hline 2 & MST1R & MST1 & 364 & 17 & 14 & 9 & $>3$ & $<0.001$ \\
\hline 1 & PDGFRA & PDGFA & 347 & 30 & 21 & 6 & 1.725 & 0.024 \\
\hline 1 & TEK & ANGPT2 & 364 & 22 & 13 & 5 & 2.670 & 0.004 \\
\hline
\end{tabular}

(B) Median months OS and DFS for combined significantly concurrent potentially oncogenic alterations (RNASeq V2 >2-fold and/or gene amplification and/or mutation as noted) for RTKs and cognate ligands in BCa TCGA dataset $(n=408)$ [21].

\begin{tabular}{|c|c|c|c|c|c|c|}
\hline RTK/Ligand: Analysis Conditions & OS or DFS & Group & $\begin{array}{l}\text { Cases, } \\
\text { Total }\end{array}$ & $\begin{array}{l}\text { Cases, Deceased or } \\
\text { Recurred Progressed }\end{array}$ & $\begin{array}{l}\text { Median } \\
\text { Months } \\
\end{array}$ & Logrank p \\
\hline \multirow{4}{*}{$\begin{array}{l}\text { AXL/CSF1R/PDGFR + Ligands: } \\
\text { exp>2, amp }\end{array}$} & \multirow{2}{*}{ OS } & Co-altered & 23 & 13 & 23.62 & \multirow{2}{*}{0.2320} \\
\hline & & Unaltered & 382 & 164 & 34.95 & \\
\hline & \multirow{2}{*}{ DFS } & Co-altered & 19 & 11 & 18.00 & \multirow{2}{*}{0.1610} \\
\hline & & Unaltered & 300 & 130 & 32.59 & \\
\hline \multirow{4}{*}{$\begin{array}{l}\text { AXL/CSF1R/PDGFR + Ligands: } \\
\text { exp>2, amp, mut }\end{array}$} & \multirow{2}{*}{ OS } & Co-altered & 25 & 14 & 23.62 & \multirow{2}{*}{0.2180} \\
\hline & & Unaltered & 380 & 163 & 34.95 & \\
\hline & \multirow{2}{*}{ DFS } & Co-altered & 21 & 13 & 18.00 & \multirow{2}{*}{0.0606} \\
\hline & & Unaltered & 298 & 128 & 32.59 & \\
\hline \multirow{4}{*}{$\begin{array}{l}\text { All RTK/Ligands w/out MST1R/MST1: } \\
\text { exp>2, amp }\end{array}$} & \multirow{2}{*}{ OS } & Co-altered & 36 & 18 & 24.28 & \multirow{2}{*}{0.2320} \\
\hline & & Unaltered & 369 & 159 & 35.38 & \\
\hline & \multirow{2}{*}{ DFS } & Co-altered & 29 & 16 & 18.00 & \multirow{2}{*}{0.1090} \\
\hline & & Unaltered & 290 & 125 & 32.59 & \\
\hline \multirow{4}{*}{$\begin{array}{l}\text { All RTK/Ligands w/out MST1R/MST1: } \\
\text { exp>2, amp, mut }\end{array}$} & \multirow{2}{*}{ OS } & Co-altered & 46 & 20 & 27.04 & \multirow{2}{*}{0.7600} \\
\hline & & Unaltered & 359 & 157 & 34.03 & \\
\hline & \multirow{2}{*}{ DFS } & Co-altered & 38 & 24 & 18.00 & \multirow{2}{*}{0.0101} \\
\hline & & Unaltered & 281 & 117 & 43.96 & \\
\hline
\end{tabular}

*exp>2: mRNA overexpression z-score > 2-fold; amp: gene amplification; mut: missense mutation, unknown significance; NA: not available. 
bioRxiv preprint doi: https://doi.org/10.1101/2020.10.15.341206; this version posted October 15,2020 . The copyright holder for this preprint (which was not certified by peer review) is the author/funder. This article is a US Government work. It is not subject to copyright under 17 USC 105 and is also made available for use under a CCO license.

Table 3. Significant co-occurrence of potentially oncogenic alteration (overexpression per RNASeq V2 >2-fold, and/or gene amplification) among EMT TAs in TCGA dataset analyzed by Robertson et al. $(n=408)$ [21] and associated median OS and PFS where noteworthy.

\begin{tabular}{|c|c|c|c|c|c|c|c|c|}
\hline \multicolumn{2}{|c|}{ Gene } & \multicolumn{4}{|c|}{ Potentially Oncogenic Alteration } & \multirow{2}{*}{$\begin{array}{l}\text { Odds Ratio } \\
(\log 2)\end{array}$} & \multirow[t]{2}{*}{ p value } & \multirow{2}{*}{$\begin{array}{l}\text { Significant difference in OS and/or } \\
\text { PFS (altered vs unaltered) }\end{array}$} \\
\hline EMT TA 1 & EMT TA 2 & Unaltered & TA 1 & TA 2 & Both & & & \\
\hline ZEB1 & ZEB2 & 363 & 16 & 13 & 12 & $>3$ & $<0.001$ & PFS 15.54 vs. $36.86, p=0.0303$ \\
\hline MYC & SNAI2 & 337 & 35 & 17 & 15 & $>3$ & $<0.001$ & none \\
\hline TWIST1 & TWIST2 & 371 & 29 & 1 & 3 & $>3$ & 0.002 & $\begin{array}{c}\text { OS } 19.68 \text { vs. } 35.38, p=0.0250 \\
\text { PFS } 16.39 \text { vs. } 37.78, p=2.491 \mathrm{e}-5\end{array}$ \\
\hline RUNX2 & ZEB1 & 366 & 10 & 23 & 5 & 2.992 & 0.002 & OS 19.38 vs. $38.21, p=5.605 e-3$ \\
\hline SNAI1 & TWIST1 & 357 & 15 & 26 & 6 & 2.457 & 0.004 & PFS 17.35 vs. $37.78, p=9.118 \mathrm{e}-3$ \\
\hline TWIST1 & ZEB2 & 353 & 26 & 19 & 6 & 2.1 & 0.009 & PFS 16.39 vs. $37.78, p=7.601 \mathrm{e}-4$ \\
\hline RUNX2 & ZEB2 & 368 & 11 & 21 & 4 & 2.672 & 0.010 & $\begin{array}{l}\text { OS } 18.65 \text { vs. } 41.72, p=0.0320 \\
\text { PFS } 14.29 \text { vs. } 36.86, p=0.0145\end{array}$ \\
\hline SNAI1 & TWIST2 & 381 & 19 & 2 & 2 & $>3$ & 0.015 & none \\
\hline TWIST2 & ZEB2 & 377 & 2 & 23 & 2 & $>3$ & 0.020 & PFS 10.35 vs. $32.59, p=5.323 \mathrm{e}-3$ \\
\hline SOX9 & TWIST1 & 346 & 26 & 26 & 6 & 1.619 & 0.031 & PFS 17.97 vs. $43.96, p=4.762 \mathrm{e}-3$ \\
\hline
\end{tabular}


bioRxiv preprint doi: https://doi.org/10.1101/2020.10.15.341206; this version posted October $15,2020$. The copyright holder for this preprint

(which was not certified by peer review) is the author/funder. This article is a US Government work. It is not subject to copyright under 17 USC 105 and is also made available for use under a CCO license.

Table 4. (A) Significant co-occurrence of potentially oncogenic alteration (overexpression $>2$-fold, and/or gene amplification) for Group 1 TKs and EMT TAs in TCGA dataset $(n=408)$ [21] and associated median OS and PFS.

\begin{tabular}{|c|c|c|c|c|c|c|c|c|}
\hline \multicolumn{2}{|c|}{ Gene } & \multicolumn{4}{|c|}{ Potentially oncogenic alteration } & \multirow{2}{*}{$\begin{array}{l}\text { Odds Ratio } \\
\text { (Log 2) }\end{array}$} & \multirow[t]{2}{*}{$P$ value } & \multirow{2}{*}{$\begin{array}{l}\text { Significant difference in OS } \\
\text { and/or PFS (altered vs unaltered) }\end{array}$} \\
\hline EMT TA & Group 1 TK & Not altered & EMT TA & TK & Both & & & \\
\hline \multirow[t]{2}{*}{ MYC } & MET & 336 & 43 & 16 & 9 & 2.136 & 0.002 & none \\
\hline & LYN & 333 & 42 & 19 & 10 & 2.061 & 0.002 & none \\
\hline \multirow[t]{3}{*}{ RUNX2 } & $\mathrm{AXL}$ & 366 & 15 & 19 & 4 & 2.361 & 0.018 & $\begin{array}{l}\text { OS } 18.89 \text { vs. } 41.72, p=0.0112 \\
\text { PFS } 15.5 \text { vs. } 36.86, p=0.0172\end{array}$ \\
\hline & FGFR1 & 342 & 13 & 43 & 6 & 1.876 & 0.018 & none \\
\hline & FYN & 365 & 15 & 20 & 4 & 2.283 & 0.02 & none \\
\hline \multirow[t]{4}{*}{ SNAI1 } & TIE1 & 346 & 17 & 33 & 8 & 2.303 & 0.002 & none \\
\hline & FGFR1 & 333 & 22 & 35 & 14 & 2.598 & $<0.001$ & none \\
\hline & $\mathrm{ABL2}$ & 337 & 29 & 31 & 7 & 1.392 & 0.04 & none \\
\hline & LYN & 350 & 25 & 18 & 11 & $>3$ & $<0.001$ & none \\
\hline \multirow[t]{3}{*}{ SOX2 } & EPHB3 & 351 & 12 & 25 & 16 & $>3$ & $<0.001$ & none \\
\hline & FYN & 350 & 30 & 19 & 5 & 1.618 & 0.046 & none \\
\hline & PTK7 & 357 & 31 & 12 & 4 & 1.941 & 0.041 & none \\
\hline \multirow[t]{7}{*}{ TWIST1 } & ABL1 & 353 & 24 & 19 & 8 & 2.631 & $<0.001$ & PFS 17.35 vs. $36.86, p=5.563 \mathrm{e}-3$ \\
\hline & DDR2 & 305 & 19 & 67 & 13 & 1.639 & 0.004 & PFS 19.09 vs. $43.17, p=0.0335$ \\
\hline & PDGFRA & 347 & 21 & 25 & 11 & 2.862 & $<0.001$ & PFS 17.35 vs. $37.78, p=2.209 \mathrm{e}-3$ \\
\hline & PDGFRB & 353 & 25 & 19 & 7 & 2.379 & 0.002 & $\begin{array}{l}\text { OS } 19.68 \text { vs. } 34.95, p=0.0424 \\
\text { PFS } 15.34 \text { vs. } 37.78, p=8.717 \mathrm{e}-5\end{array}$ \\
\hline & TIE1 & 339 & 24 & 33 & 8 & 1.776 & 0.009 & $\begin{array}{c}\text { OS } 26.91 \text { vs. } 41.72, \mathrm{p}=0.0256 \\
\text { PFS } 16.79 \text { vs. } 37.78, \mathrm{p}=1.361 \mathrm{e}-3\end{array}$ \\
\hline & TEK & 351 & 26 & 21 & 6 & 1.948 & 0.014 & PFS 16.79 vs. $36.86, p=4.532 \mathrm{e}-4$ \\
\hline & ROR2 & 350 & 26 & 22 & 6 & 1.876 & 0.016 & none \\
\hline \multirow[t]{5}{*}{ TWIST2 } & FYN & 379 & 1 & 21 & 3 & $>3$ & $<0.001$ & none \\
\hline & ABL1 & 375 & 2 & 25 & 2 & $>3$ & 0.024 & none \\
\hline & PDGFRA & 366 & 2 & 34 & 2 & $>3$ & 0.041 & PFS 18.00 vs. $36.86, p=0.0312$ \\
\hline & PDGFRB & 376 & 2 & 24 & 2 & $>3$ & 0.022 & PFS 10.05 vs. $36.86, p=6.630 \mathrm{e}-4$ \\
\hline & TEK & 375 & 2 & 25 & 2 & $>3$ & 0.024 & none \\
\hline \multirow[t]{14}{*}{ ZEB1 } & ABL1 & 348 & 29 & 15 & 12 & $>3$ & $<0.001$ & none \\
\hline & DDR2 & 301 & 23 & 62 & 18 & 1.926 & $<0.001$ & none \\
\hline & CSFR1 & 341 & 31 & 22 & 10 & 2.322 & $<0.001$ & none \\
\hline & $\mathrm{AXL}$ & 347 & 34 & 16 & 7 & 2.159 & 0.005 & none \\
\hline & FYN & 346 & 34 & 17 & 7 & 2.067 & 0.006 & none \\
\hline & ITK & 344 & 35 & 19 & 6 & 1.634 & 0.031 & none \\
\hline & FGFR1 & 323 & 32 & 40 & 9 & 1.183 & 0.044 & none \\
\hline & ROR1 & 348 & 30 & 15 & 11 & $>3$ & $<0.001$ & none \\
\hline & TEK & 347 & 30 & 16 & 11 & 2.991 & $<0.001$ & none \\
\hline & TIE1 & 335 & 28 & 28 & 13 & 2.474 & $<0.001$ & none \\
\hline & PDGFRA & 339 & 29 & 24 & 12 & 2.547 & $<0.001$ & none \\
\hline & PTK7 & 354 & 34 & 9 & 7 & $>3$ & $<0.001$ & none \\
\hline & PDGFRB & 345 & 33 & 18 & 8 & 2.216 & 0.002 & none \\
\hline & ROR2 & 343 & 33 & 20 & 8 & 2.056 & 0.004 & none \\
\hline
\end{tabular}


bioRxiv preprint doi: https://doi.org/10.1101/2020.10.15.341206; this version posted October 15,2020 . The copyright holder for this preprint (which was not certified by peer review) is the author/funder. This article is a US Government work. It is not subject to copyright under 17 USC 105 and is also made available for use under a CCO license.

Table 4. (B) Significant co-occurrence of potentially oncogenic alteration (overexpression $>2$-fold, and/or gene amplification) for Group 2 TKs and EMT TAs in TCGA dataset $(n=408)$ [21] and associated median OS and PFS.

\begin{tabular}{|c|c|c|c|c|c|c|c|c|}
\hline \multicolumn{2}{|c|}{ Gene } & \multicolumn{4}{|c|}{ Potentially oncogenic alteration } & \multirow{2}{*}{$\begin{array}{l}\text { Odds Ratio } \\
\text { (Log 2) }\end{array}$} & \multirow[t]{2}{*}{$P$ value } & \multirow{2}{*}{$\begin{array}{l}\text { Significant difference in OS } \\
\text { and/or PFS (altered vs. not) }\end{array}$} \\
\hline EMT TA & Group 2 TK & Not altered & EMT TA & TK & Both & & & \\
\hline \multirow[t]{2}{*}{ MYC } & PTK2 & 333 & 33 & 19 & 19 & $>3$ & $<0.001$ & none \\
\hline & TXK & 340 & 44 & 12 & 8 & 2.365 & 0.002 & none \\
\hline \multirow[t]{2}{*}{ SNAI1 } & PTK2 & 341 & 25 & 27 & 11 & 2.474 & $<0.001$ & none \\
\hline & TYK2 & 356 & 20 & 23 & 5 & 1.952 & 0.022 & none \\
\hline SNAI2 & PTK2 & 341 & 25 & 27 & 11 & 2.474 & $<0.001$ & none \\
\hline \multirow[t]{2}{*}{ SOX2 } & TNK2 & 352 & 14 & 24 & 14 & $>3$ & $<0.001$ & none \\
\hline & TYK2 & 353 & 23 & 23 & 5 & 1.738 & 0.035 & none \\
\hline ZEB1 & DDR1 & 344 & 35 & 19 & 6 & 1.634 & 0.031 & none \\
\hline
\end{tabular}




\section{Figure Legends}

Figure 1. Heat map showing relative mRNA expression levels (RNA Seq V2) of 52 tyrosine kinases (TK, gene symbols listed vertically at right) among 408 tumor samples from patients with muscle invasive bladder cancer (MIBC) [21]. Samples are grouped on the horizontal axis by mRNA subtype classifications as defined by Robertson et al. [21] indicated at the top (from left to right): neuronal (N, green); basal squamous (BS, red); luminal (L, gray); luminal infiltrating (LI, gold); luminal papillary (LP, purple). TK genes are clustered hierarchically; in the cladogram at left cabozantinib targets are designated with violet squares.

Figure 2. Kaplan-Meier analyses of OS (left) and DFS (right) in patients harboring significant mRNA overexpression (z-score >2) and/or amplification of (A) group 1 TKs (red) vs. those without alteration (blue; median OS 28.22 vs. 61.40 mos., log-rank p=0.0308; median DFS 27.99 vs. 82.42 mos., log-rank p=0.0145); (B) group 2 TKs (red) vs. those without alteration (blue; 46.65 vs. 22.14 mos., log-rank p=3.197e-4; median DFS 51.41 vs. 19.05 mos., log-rank p=6.673e-4); (C) group 3 TKs (red) vs. those without alteration (blue; 30.91 vs. 59.26 mos., log-rank p=0.134; median DFS 27.99 vs. 72.34 mos., log-rank p=0.0391); (D) 14 ctRTKs (AXL, CSF1R, FLT3, KDR, MET, MERTK, NTRK1/2/3, RET, ROS1, TEK, DDR2 and TYR03; red) vs. those without alteration (blue; 25.56 vs. 54.86 mos., log-rank p=0.0289; median DFS 25.23 vs. 55.16 mos., log-rank $\mathrm{p}=0.0109)$.

Figure 3. (A) Heat maps of relative mRNA expression levels in 408 tumor samples from patients with MIBC [21] (RNA Seq V2, left) and absolute mRNA copy number in 15 BCa cell lines (right) of 31 TKs (gene symbols listed vertically, middle). MIBC patient tumor samples are grouped on the horizontal axis by mRNA subtype classifications as previously defined [21] indicated at the top (from left to right): neuronal (N, green); basal squamous (BS, red); luminal (L, gray); luminal infiltrating (LI, gold); luminal papillary (LP, purple). TK genes are clustered hierarchically; colored vertical bars at indicate group 1 TKs (black) above group 2 TKs (orange). Highest expression is shown in yellow, moderate expression in blue and lowest expression in black; ND for cell line data indicates transcript was undetectable. (B) Cladogram of 34 receptor TKs (RTKs) most closely related to Met based on TK domain amino acid sequence identity, constructed using the EMBL-EBI 
ClustalW2 Phylogeny tool (http://www.ebi.ac.uk/Tools/phylogeny/clustalw2_phylogeny). RTK symbol colors identify established subfamilies. Values for cabozantinib doses calculated to provide $50 \% \mathrm{TK}$ inhibition $\left(\mathrm{IC}_{50}, \mathrm{nM}\right.$ ) in a cell-free assay, listed at right, were derived from a minimum of $3 \times 10$-dose binding curves with regression (R) values $>0.98$ unless indicated by NC (not calculated), where values were $>3 \mathrm{uM}$. Values considered clinically relevant $(<150 \mathrm{nM})$ are shown in red. TKs for which $\mathrm{IC}_{50}$ values could not be determined are denoted by a single dash. (C) Oncoprint showing alterations for 19 genes encoding ctRTKs (identified previously and/or by cellfree kinase inhibition assay) among 408 MIBC samples [21]. Gene symbols and percentage of samples altered (\%) for each are listed at left (Oncoprint generated using visualization tools at the cBioPortal for Cancer Genomics, Memorial Sloan Kettering Cancer Center, https://www.cbioportal.org/ [34]). (D) Linear regression analysis of $A X L$ (left) and MET (right) mRNA abundance (y-axis) vs. protein content ( $\mathrm{x}$-axis) for $15 \mathrm{BCa}$-derived cell lines shows significant direct correlation (AXL: Spearman $\mathrm{r}=0.638, \mathrm{p}=0.040 ;$ MET: Spearman $\mathrm{r}=0.7902, \mathrm{p}=$ 0.003).

Figure 4. (A) Heat map showing relative mRNA expression levels of ctRTK-cognate ligand pairs (RNA Seq V2) among 408 tumor samples from patients with MIBC [21] (left), and among 15 BCaderived cell lines (absolute mRNA copy number, right). (B) Immunoblot detection of ctRTKs and their cognate ligands, CSF1/CSF1R, GAS6/AXL, MST1/MST1R in 9 BCa-derived cell lines. (C) Left: heat map showing relative mRNA expression levels of 9 EMT-associated transcriptional activators (listed at right) among 408 tumor samples from patients with MIBC [21]. Samples are grouped on the horizontal axis by mRNA subtype classifications defined previously [21] indicated at the top (from left to right): neuronal (N, green); basal squamous (BS, red); luminal (L, gray); luminal infiltrating (LI, gold); luminal papillary (LP, purple), and clustered hierarchically on the vertical axis. Right: heat map showing absolute mRNA copy levels of 9 EMT-associated transcriptional activators among 15 BCa-derived cell lines (identified at bottom)

Figure 5. (A) Left: Axl kinase activation (phospho-Axl/total-Axl protein, pAxl/tAxl), as determined by 2 -site immunoassay, in serum-deprived $J 82$ cells treated with Gas6 $\left(5.7 \mathrm{nM}, 1 \mathrm{~h}\right.$ at $\left.37^{\circ} \mathrm{C}\right)$ in the presence or absence of cabozantinib (cabo; $300 \mathrm{nM}$ ), relative to untreated cells. Maximum possible Axl kinase activation was measured by adding ATP during the immunoassay (20 uM, 20 
min at $25^{\circ} \mathrm{C}$ ) of lysates prepared from untreated J82 cells. Right top: Axl kinase activation (pAxl/tAxl) in serum-deprived J82 cells that had been transfected with GAS6 siRNA or scrambled (control) siRNA. In both panels, values are the mean +/- SD from triplicate samples; asterisks indicate significant difference from untreated control $(\mathrm{p}<0.05)$. Right bottom: ethidium bromide visualization of PCR products specific for GAS6 mRNA (upper panel) vs 18S rRNA (lower panel) resolved by agarose gel electrophoresis. (B) Left: Akt kinase activation (pAkt/tAkt), as determined by 2 -site immunoassay, in serum-deprived J82 cells treated with Gas6 $\left(5.7 \mathrm{nM}, 1 \mathrm{~h}\right.$ at $\left.37^{\circ} \mathrm{C}\right)$ in the presence or absence of cabozantinib (cabo; $300 \mathrm{nM}$ ), relative to untreated cells. Right: Akt kinase activation (pAkt/tAkt) in serum-deprived J82 cells that had been transfected with Gas6 siRNA or scrambled (control) siRNA. In both panels, values are the mean +/- SD from triplicate samples; asterisks indicate significant difference from untreated control ( $\mathrm{p}<0.05)$. (C) Left: Erk kinase activation (pErk/tErk), as determined by 2-site immunoassay, in serum-deprived J82 cells treated with Gas6 (5.7 nM, $1 \mathrm{~h}$ at $\left.37^{\circ} \mathrm{C}\right)$ in the presence or absence of cabozantinib (cabo; $300 \mathrm{nM}$ ), relative to untreated cells. Right: Erk kinase activation (pErk/tErk) in serum-deprived J82 cells that had been transfected with GAS6 siRNA or scrambled (control) siRNA. In both panels, values are the mean +/- SD from triplicate samples; asterisks indicate significant difference from untreated control (p < 0.05). (D) Upper panels: Immunoblot (IB) of phospho-MST1R (pMST1R) and MST1R (left) or pCSF1R and CSF1R (right) in lysates from serum-deprived FL3 cells after transfection with siRNA directed against MST1 (siMST1, left) or CSF1 (siCSF1, right) or control siRNA (siCont). Lower panels: Ethidium bromide visualization of PCR products (PCR) specific for MST1 (left) or CSF1 (right) mRNA or 18S RNA resolved by agarose gel electrophoresis. (E) Left: Akt kinase activation (pAkt/tAkt) in serum-deprived FL3 cells treated with MST1 (5 nM) or CSF1 (10 nM) in the presence or absence of cabozantinib (cabo; $300 \mathrm{nM}$ ), relative to untreated cells. Right: Akt kinase activation (pAkt/tAkt) in FL3 cells that had been transfected with siRNA directed against CSF1 or MST1, or with control siRNA. In both panels, values are the mean +/- SD from triplicate samples; asterisks indicate significant difference from control $(\mathrm{p}<0.05)$. (F) Left: Erk kinase activation (pErk/tErk) in serum-deprived J82 cells treated with MST1 or CSF1 in the presence or absence of cabozantinib (cabo), relative to untreated cells. Right: Erk kinase activation (pErk/tErk) in FL3 cells that had been transfected with siRNA directed against CSF1 or MST1, or with control siRNA. In both panels, values are the mean +/- SD from triplicate samples; asterisks 
indicate significant difference from untreated control $(\mathrm{p}<0.05)$. All results are representative of at least 3 experiments.

Figure 6. (A) Migration $\left(16 \mathrm{~h}, 37^{\circ} \mathrm{C}\right)$ of serum-deprived J82 cells previously transfected with siRNA directed against AXL (siAXL) or control siRNA (siControl), treated with Gas6 (5.7 nM) in the presence or absence of cabozantinib (cabo; $300 \mathrm{nM}$ ), relative to untreated cells. Values are the mean +/- SD from triplicate samples; asterisks indicate significant difference from control (p < 0.05; ns, not significant). All results are representative of at least 3 experiments. Inset: ethidium bromide visualization of PCR products specific for AXL mRNA (upper panel) or 18S rRNA (lower panel) resolved by agarose gel electrophoresis. (B) Migration (16 h, 37 $\left.{ }^{\circ} \mathrm{C}\right)$ of serum-deprived FL3 cells previously transfected with siRNA directed against MST1R (siMST1R), CSF1R (siCSF1R) or control siRNA (siControl), treated with MST1 (5 nM) or CSF1 (10 nM) in the presence or absence of cabozantinib (cabo; $300 \mathrm{nM}$ ), relative to untreated cells. Values are the mean +/- SD from triplicate samples; asterisks indicate significant difference from untreated control $(\mathrm{p}<0.05)$. All results are representative of at least 3 experiments. Inset: ethidium bromide visualization of PCR products specific for MST1R, (upper panel), CSF1R (middle panel), or 18S RNA (lower panel) resolved by agarose gel electrophoresis. (C) Proliferation (cell no. x 10-5, $6 \mathrm{~d}, 37^{\circ} \mathrm{C}$ ) of 5637 (left) or J82 (right) cells in 1\% FBS left untreated (control; circles) or treated with Gas6 alone (5.7 nM; squares), cabozantinib alone (300 nM, triangles) or Gas6 and cabozantinib (inverted triangles). Media with additives was replaced on days 1,2, and 4; cells were counted on days 0, 3 and 6. Values are the mean +/- SD from triplicate samples; asterisks indicate significant difference from control $(\mathrm{p}<0.05)$. (D) Proliferation (cell no. $x 10^{-5}, 6 \mathrm{~d}, 37^{\circ} \mathrm{C}$ ) of FL3 cells in $1 \%$ FBS left untreated (control; circles) or treated with MST1 alone (5 nM; squares), cabozantinib alone (300 nM, triangles) or MST1 and cabozantinib (inverted triangles). Media replacement and cell counting as per panel C. Values are the mean +/- SD from triplicate samples; asterisks indicate significant difference from control $(\mathrm{p}<0.05)$.

Figure 7. (A) PCR products showing siRNA suppression (upper and middle panels in each group) vs. 18S rRNA loading controls (lower panel in each group) resolved by agarose gel electrophoresis and visualized using ethidium bromide staining, from cell lines used for results shown in panels B - F. Upper left: J82 cells transfected with siRNA directed against GAS6 or AXL used for results 
shown in panel B. Upper middle: FL3 cells transfected with siRNA directed against MST1 or MST1R used for results shown in panel C. Upper right: FL3 cells transfected with siRNA directed against CSF1 or CSF1R used for results shown in panel D. Lower left: J82 cells transfected with siRNA directed against AXL used for results shown in panel E. Lower right: FL3 cells transfected with siRNA directed against MST1R or CSF1R used for results shown in panel F. (B) Proliferation (abs at $570 \mathrm{~nm}, 3 \mathrm{~d}, 37^{\circ} \mathrm{C}$ ) of J82 cells in 1\% FBS previously transfected with siRNA directed against GAS6 (siGAS6), AXL (siAXL) or control siRNA (siControl) that were left untreated or treated with Gas6 (5.7 nM) in the absence or presence of cabozantinib (cabo, $300 \mathrm{nM}$ ). (C) Proliferation of FL3 cells in 1\% FBS previously transfected with siRNA directed against MST1 (siMST1), MST1R (siMST1R) or control siRNA (siControl) that were left untreated or treated with MST1 (5 nM) in the absence or presence of cabozantinib (cabo, $300 \mathrm{nM}$ ). (D) Proliferation of FL3 cells in 1\% FBS previously transfected with siRNA directed against CSF1 (siCSF1), CSF1R (siCSFR) or control siRNA (siControl) that were left untreated or treated with CSF1 (10 nM) in the absence or presence of cabozantinib (cabo, $300 \mathrm{nM}$ ). (E) Anchorage independent growth (abs at $570 \mathrm{~nm}$ ) of J82 cells in 1\% FBS previously transfected with siRNA directed against AXL (siAXL) or control siRNA (siControl) that were left untreated or treated with Gas6 (5.7 nM) in the absence or presence of cabozantinib (cabo, $300 \mathrm{nM}$ ). (F) Anchorage independent growth of FL3 cells in 1\% FBS previously transfected with siRNA directed against MST1R (siMST1R), CSF1R (siCSFR) or control siRNA (siControl) that were left untreated or treated with MST1 (5 nM) or CSF1 (10 nM) in the absence or presence of cabozantinib (cabo, $300 \mathrm{nM}$ ). In panels C - F, values are the mean +/SD from triplicate samples; asterisks indicate significant difference from untreated control $(\mathrm{p}<$ 0.05 , ns, not significant). In all panels, data are representative of 3 or more independent experiments.

Figure 8. (A) Tumor volume $\left(\mathrm{mm}^{3}\right.$ ) of individual J82 (left) or MDXC1 (middle) cell xenografts in mice, or mean (+/- SD) tumor growth of both cell line xenografts (right), vs. days post implantation. (B) mRNA expression levels of $A X L$, TYRO3, MERTK, CSF1R, RET, MET, KDR, GAS6, KIT and MST1R in J82 cells and 8 J82 tumor-derived cell lines (MDXC1, MDXC2, MDXC31R, MDXC31L, MDXC33R, MDXC33L, MDXC34R and MDXC34L) as determined by qRT-PCR. (C) Immunoblot of lysates from J82 and MDXC1 lysates for phospho-MERTK (pMERTK, upper panels), MERTK (middle panels) or GAPDH (lower panels); intact cells had been treated prior to lysis with Gas6 
(5.7 nM) or TP0903 (300 nM) as indicated. Results are representative of 3 or more independent experiments. (D) Light micrographs (10x objective magnification) of stained J82 (upper panels) of MDXC1 (lower panels) $24 \mathrm{~h}$ cell migration in the absence (control, left) or presence of added Gas6 (Gas6, $5.7 \mathrm{nM}$, right). (E) Heat map showing relative mRNA expression levels of 321 genes of the 770 gene Nanostring PanCancer Progression Panel (clustered hierarchically) that were significantly different among untreated J82 (left) and MDXC1 (right) cells (two-group comparison $\mathrm{p}=0.021, \mathrm{q}=0.05 ;$ Table S5). 
Supplement Tables S1 - S5: MS Excel file: “Tables S1-S5.xlsx”

Table S1. (A) List of 89 TKs by Gene ID, Protein Name, and Group Status. (B) Expression profiles (RNA Seq V2 z-scores) of 89 TKs among 408 patient tumor samples as reported by Robertson et al. [21].

Table S2. (A) Overall and disease-free survival values for cases with amplification (amp), or significant overexpression (exp>2, z-score $>2$; exp>4, z-score >4) of 89 TKs listed in Table S1. (B) Overall and disease-free survival values for cases with amplification and/or significant overexpression (z-score >2) of Group 1 TKs. (C) Overall and disease-free survival values for cases with amplification and/or significant overexpression (z-score >2) of Group 2 TKs. (D) Overall and disease-free survival values for cases with amplification and/or significant overexpression (zscore >2) of Group 3 TKs. (E) Overall and disease-free survival values for cases with amplification and/or significant overexpression (z-score $>2$ ) of 14 ctRTKs. (F) Overall and disease-free median survival values (in months) for cases with amplification and/or significant overexpression (zscore >2) and/or RTK mutation (mut; missense mutations) of RTK/ligand pairs, singly and in various combinations.

Table S3. (A) Significant co-occurrence of overexpression (exp>2) and/or gene amplification (amp) among Group 1 TKs; (B) Significant co-occurrence of overexpression and/or gene amplification among Group 2 TKs; (C) Significant co-occurrence of overexpression and/or gene amplification among Group 3 TKs; (D) Significant co-occurrence of overexpression and/or gene amplification and/or mutation among ctRTKs.

Table S4. (A) Nanostring PanCancer Progression 770 gene panel using original Nanostring annotations for gene groupings. (B) Expression levels of 321 genes from the PanCancer Progression panel which were significantly different between J82 and MDXC1 cell lines, used as the source file for subsequent Ingenuity Pathway Analyses. Fold change is listed for J82 relative to MDXC1, e.g. ACTG2 (actin gamma 2, smooth muscle) is 91.773-fold more highly expressed in J82 than in MDXC1. 
Table S5. Ingenuity Pathway Analysis (IPA) results of 321 differentially expressed genes from the Nanostring PanCancer Progression 770 gene panel that distinguish J82 cells from the derivative MDXC1 cell line. (A) IPA Diseases and Bio-functions. A positive IPA z-score indicates direct concordance between the direction (expression increase or decrease) and of genes altered in the sample and genes included in the IPA subcategory, a negative score indicates an inverse concordance. The IPA z-score is unrelated to the magnitude of expression change, provided it exceeds a threshold defined on the basis of p-value and q-value (false discovery rate). B-H p-value indicates p-value with Benjamini and Hochberg multiple test correction. (B) IPA Upstream Regulators; B-H p-value indicates p-value with Benjamini and Hochberg multiple test correction. (C) IPA Canonical Pathways; Z-score = NaN indicates that a z-score could not be computed. 
bioRxiv preprint doi: https://doi.org/10.1101/202010.15.341206; this version posted October 15, 2020. The copyright holder for this preprint (which was not certified by peer review) is the author/funder. This article is a US Government work. It is not subject to copyright under 17 USC

Lee et al., Figure 1 105 and is also made available for use under a CCO license.

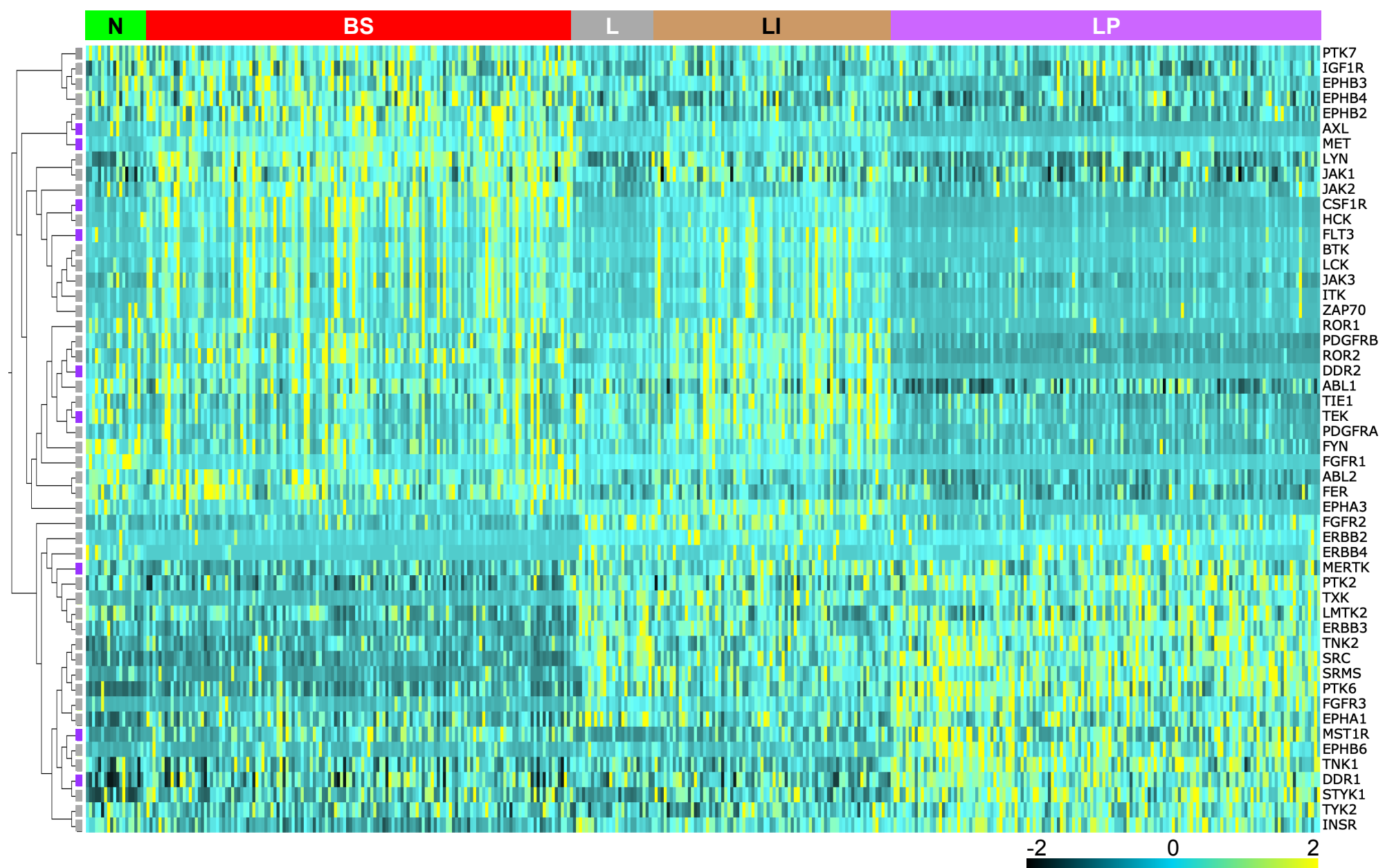


bioRxiv preprint doi: https://doi.org/10.1101/2020.10.15.341206; this version posted October 15, 2020. The copyright holder for this preprint (which was not certified by peer review) is the author/funder. This article is a US Government work. It is not subject to copyright under 17 USC Lee et al., Figure 2 105 and is also made available for use under a CCO license.
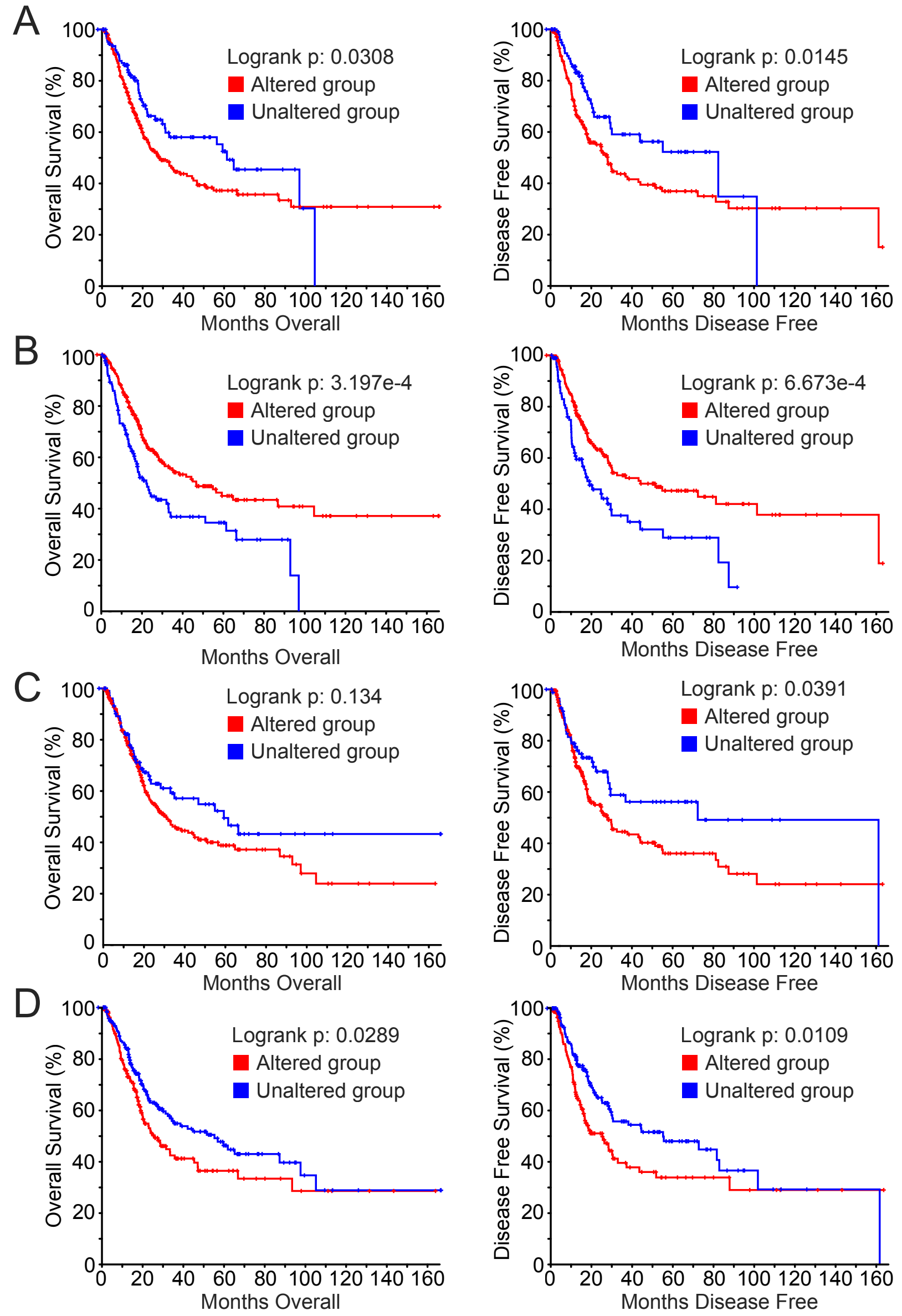
bioRxiv preprint doi: https://doi.org/10.1101/2020.10.15.341206; this version posted October 15, 2020. The copyright holder for this preprint

(which was not certified by peer review) is the author/funder. This article is a US Government work. It is not subject to copyright under 17 USC

Lee et al., Figure 3 105 and is also made available for use under a CCO license.
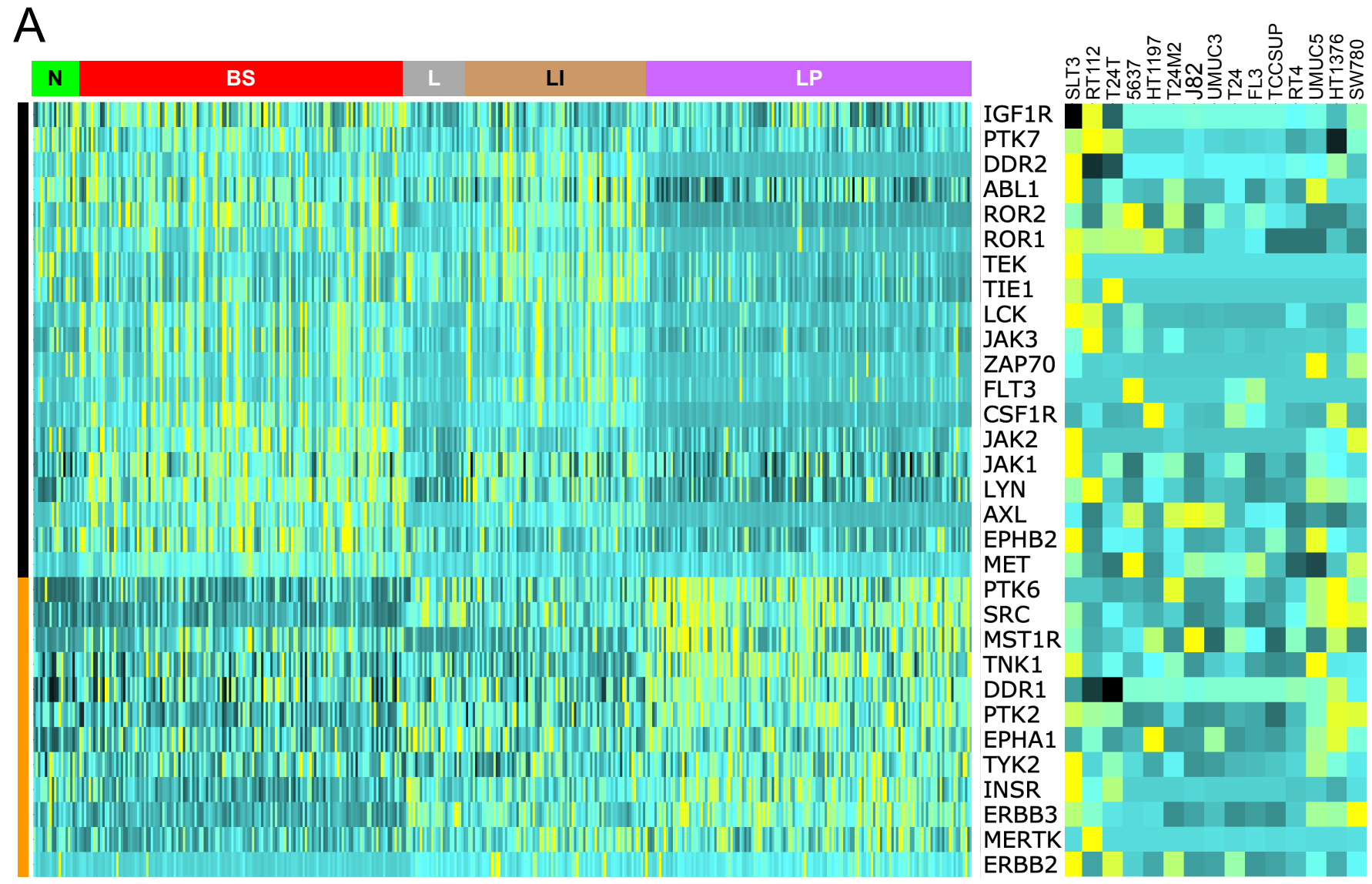

B

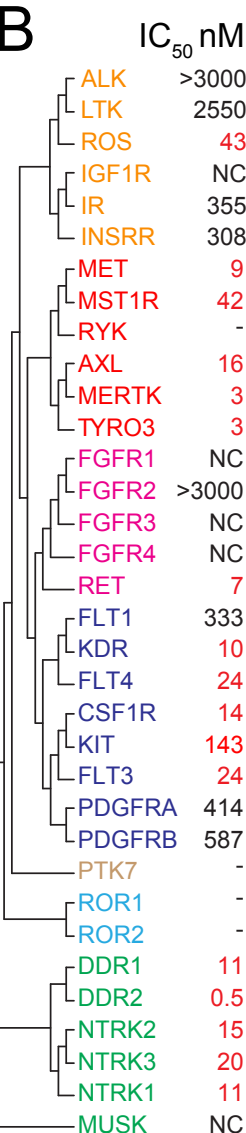

C

Gene ID (\%)

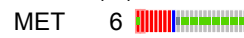

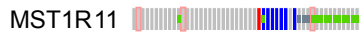

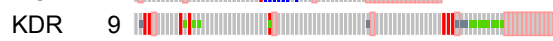

RET $\quad 6$ :

FLT1 8 8

FLT4 7 F 7 ||

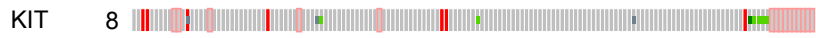

FLT3 7 7 7 -

ROS1 8 |

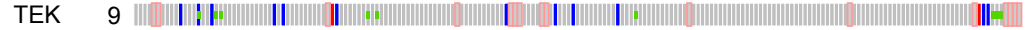

AXL 6 G

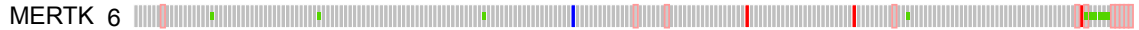

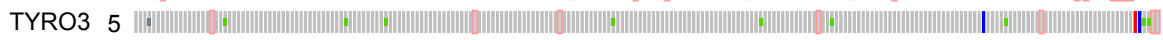

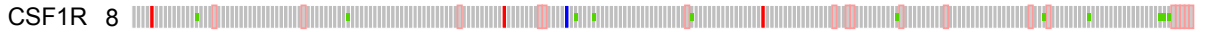

DDR1 6 |

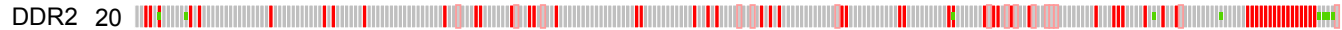

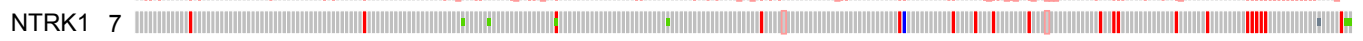

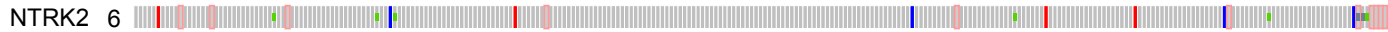

NTRK3 4 S
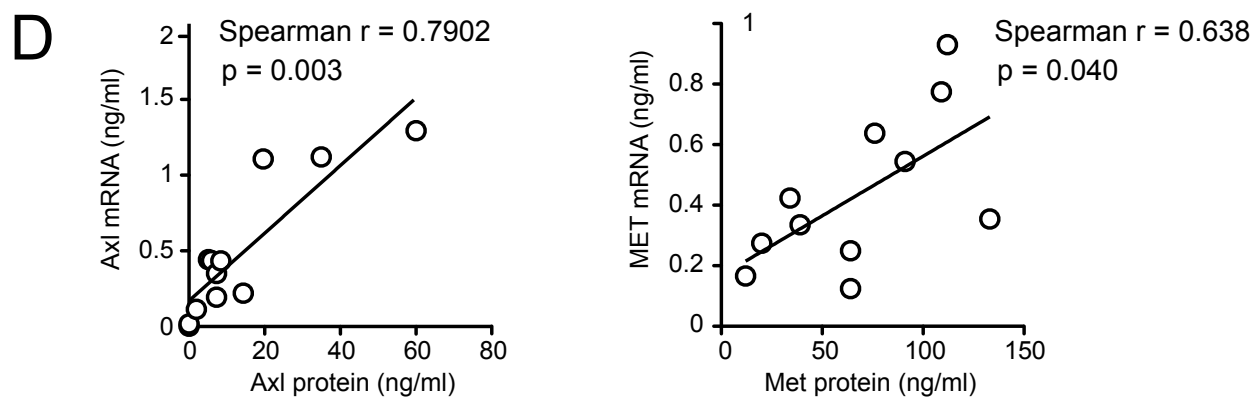
bioRxiv preprint doi: https://doi.org/10.1101/2020.10.15.341206; this version posted October 15, 2020. The copyright holder for this preprint (which was not certified by peer review) is the author/funder. This article is a US Government work. It is not subject to copyright under 17 USC Lee et al., Figure 4

A
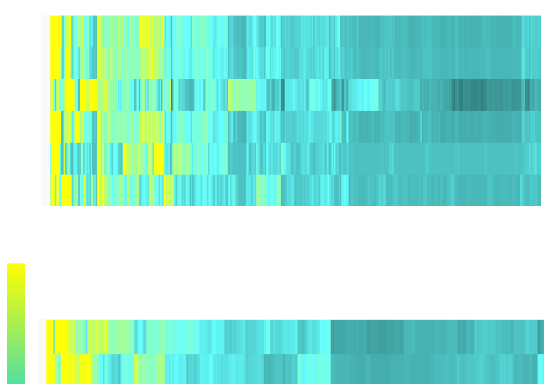

0

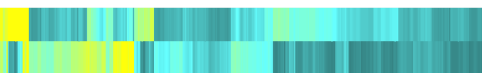

$-2$

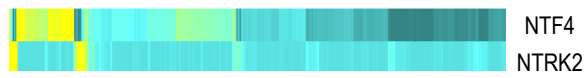

NTRK2

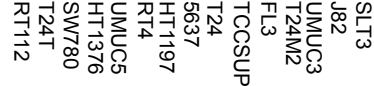

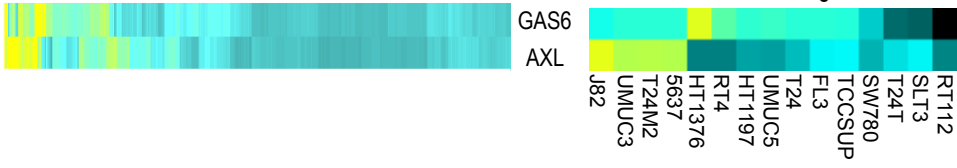

B

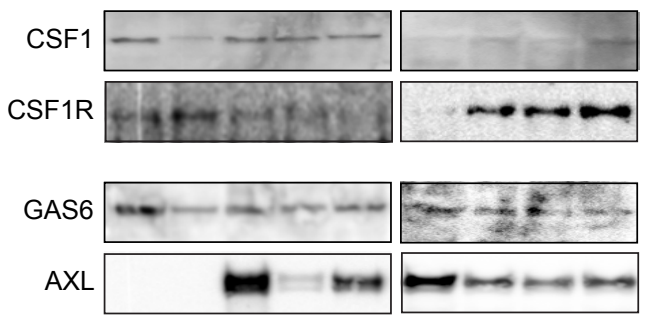

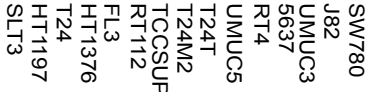

MST1

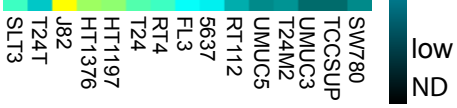

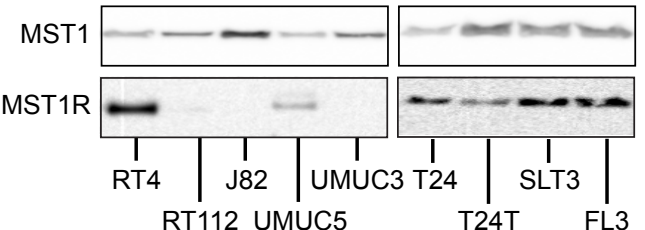

C

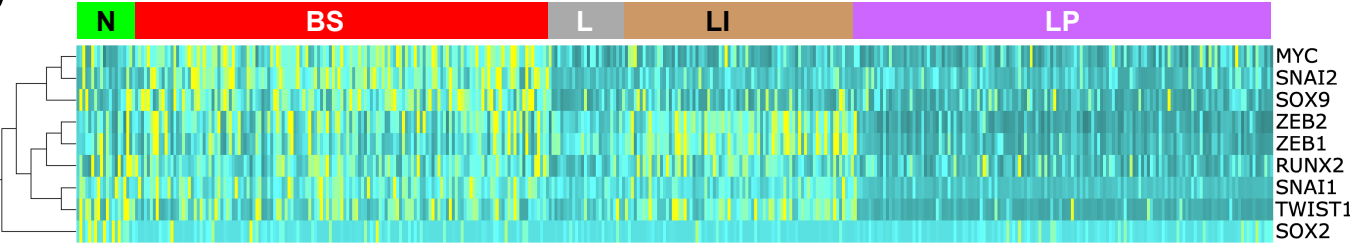



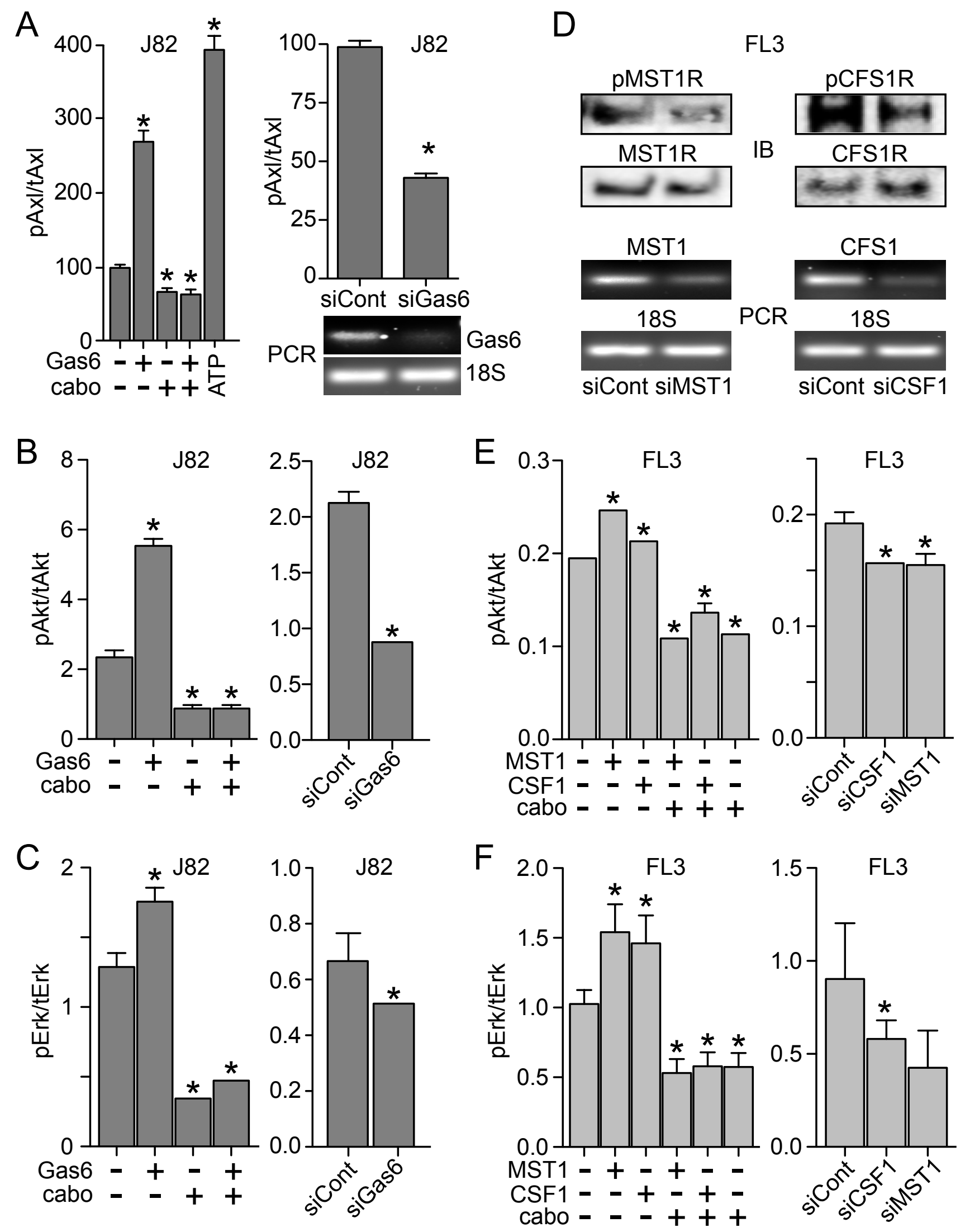


\section{Lee et al., Figure 6}
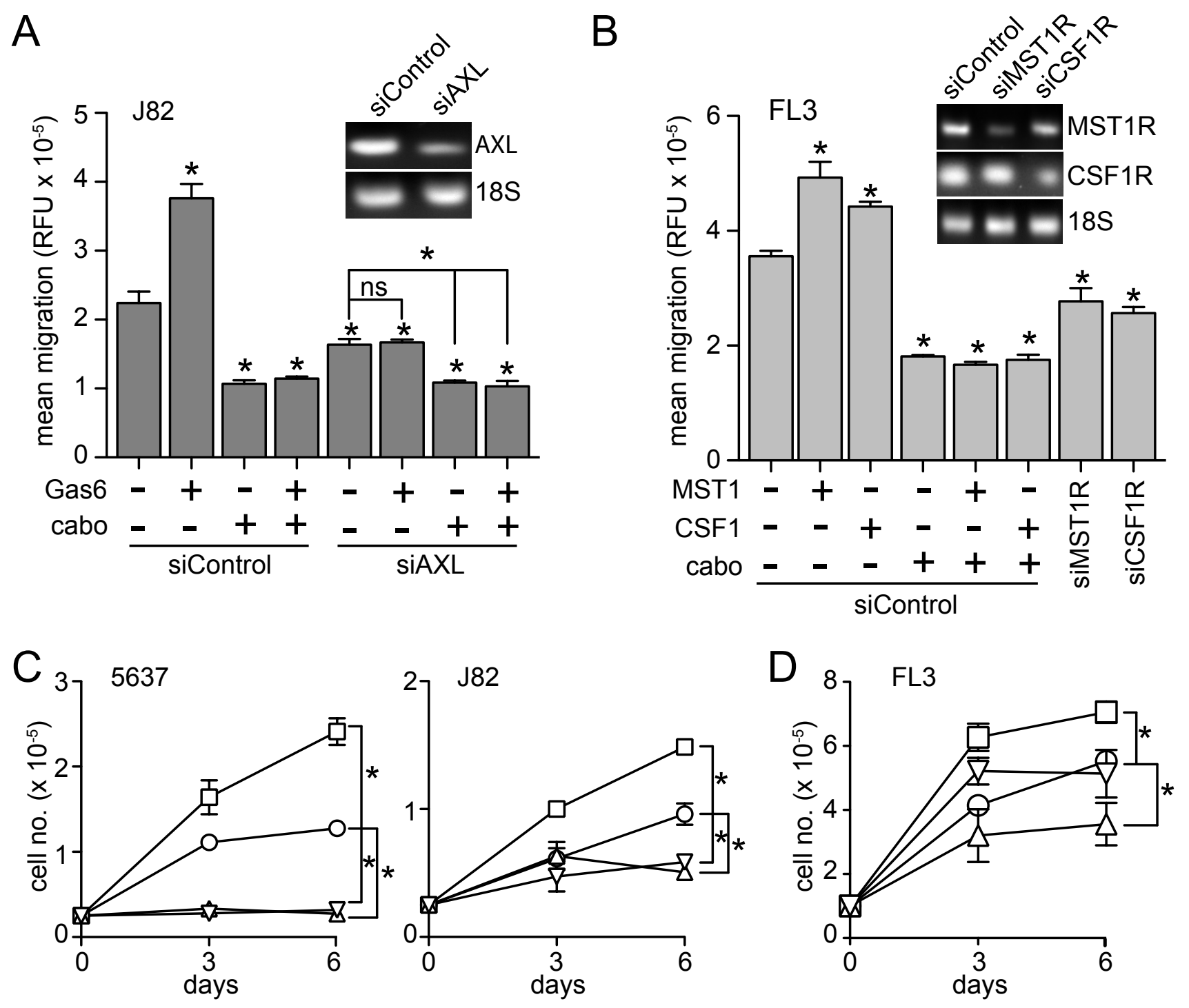
A

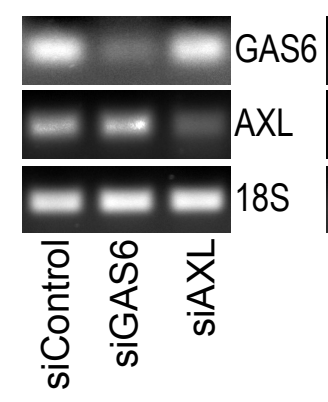

C

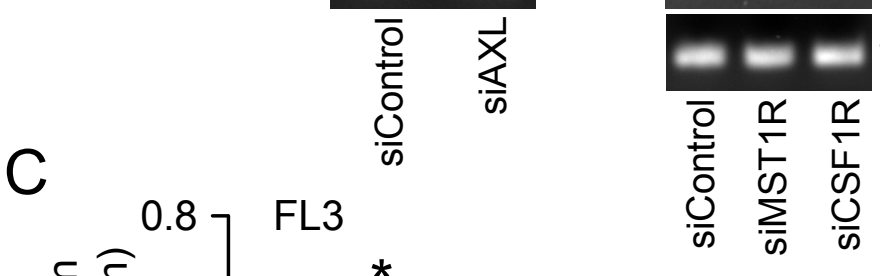

B

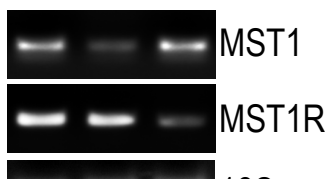

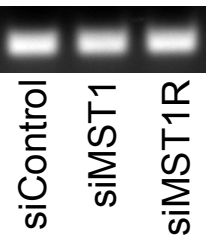

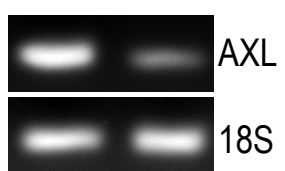

을 $18 S$

$18 S$

CSF1

CSF1R $18 \mathrm{~S}$
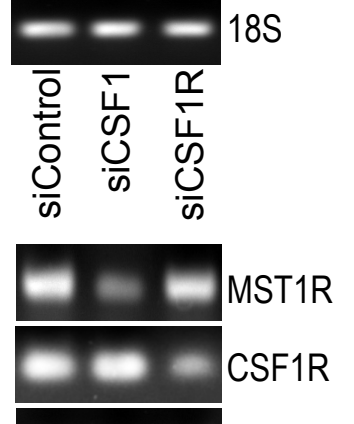

$18 \mathrm{~S}$

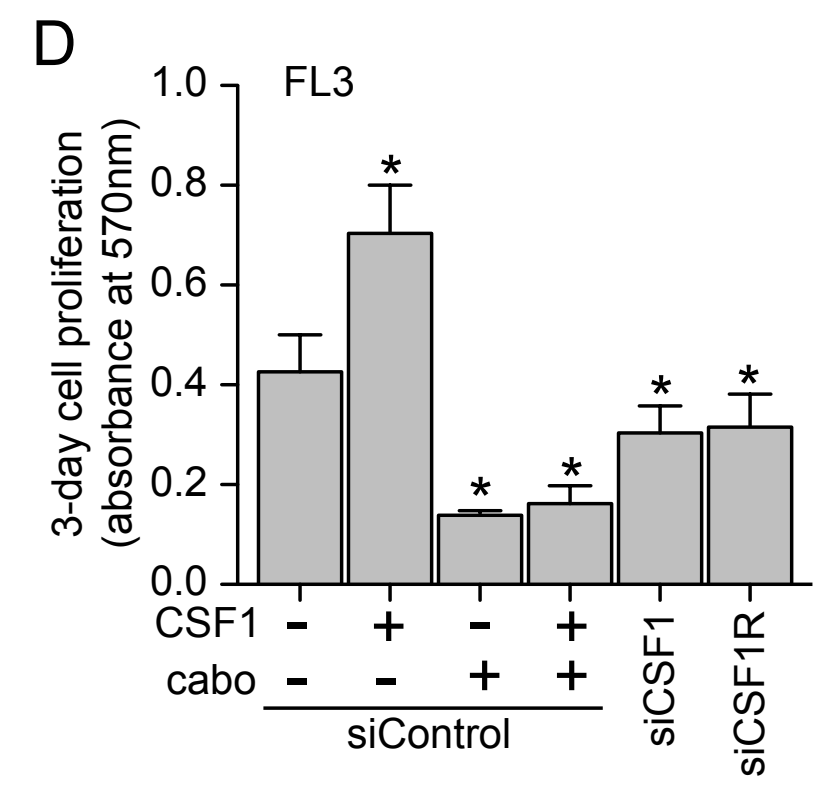

F

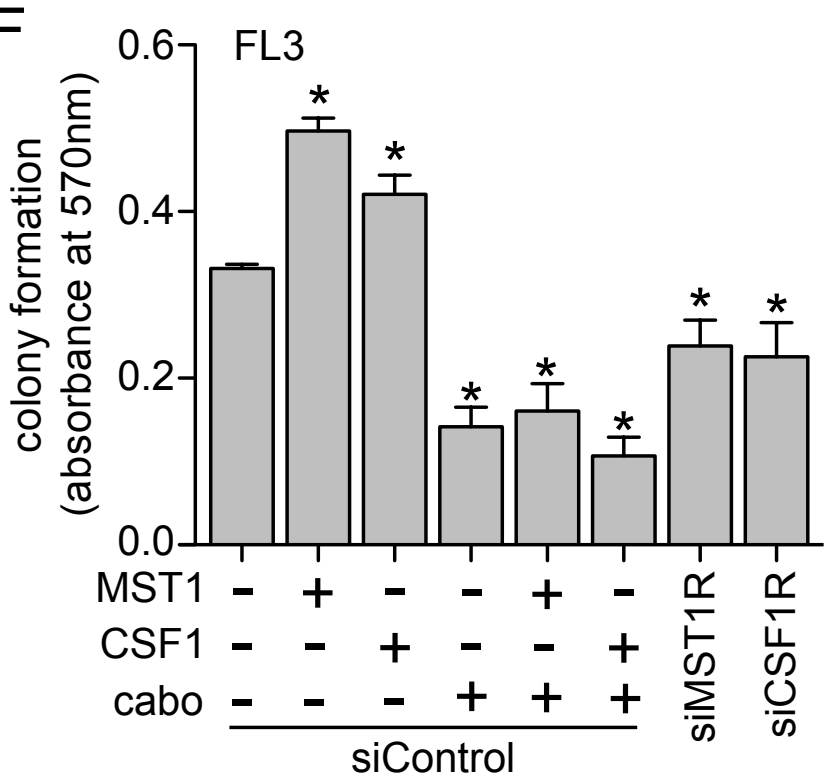


bioRxiv preprint doi: https://doi.org/10.1101/2020.10.15.341206; this version posted October 15, 2020. The copyright holder for this preprint (which was not certified by peer review) is the author/funder. This article is a US Government work. It is not subject to copyright under 17 USC Lee et al., Figure 8 105 and is also made available for use under a CCO license.
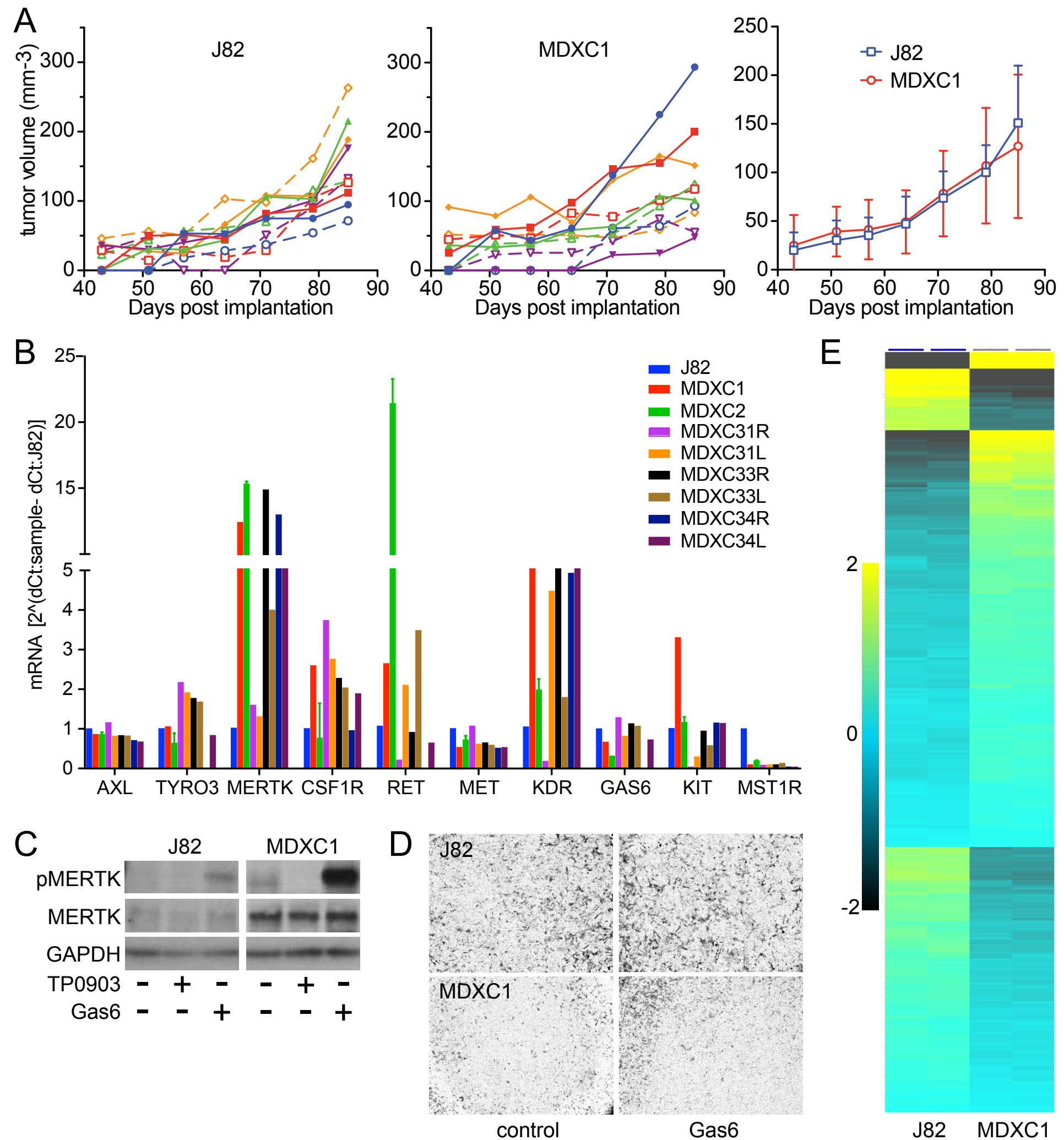

2

0

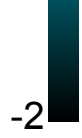

